\title{
Exploration of the personalized immune checkpoint atlas of plasma cell dyscrasias patients using high-dimensional single-cell analysis
}

\author{
CHENGGONG TU $^{1 *}$, YONGJIANG ZHENG ${ }^{2 *}$, HUI ZHANG $^{1}$ and JINHENG WANG ${ }^{1}$ \\ ${ }^{1}$ Affiliated Cancer Hospital \& Institute of Guangzhou Medical University, Guangzhou Municipal and Guangdong Provincial \\ Key Laboratory of Protein Modification and Degradation, School of Basic Medical Sciences, State Key Laboratory of \\ Respiratory Disease, Guangzhou Medical University, Guangzhou, Guangdong 510095; ${ }^{2}$ Department of Hematology, \\ The Third Affiliated Hospital of Sun Yat-Sen University, Guangzhou, Guangdong 510630, P.R. China
}

Received October 19, 2019; Accepted April 1, 2020

DOI: 10.3892/or.2020.7587

\begin{abstract}
Immune checkpoint blockade endows patients with unparalleled success in conquering cancer. Unfortunately, inter-individual heterogeneity causes failure in controlling tumors in many patients. Emerging mass cytometry technology is capable of revealing a multiscale onco-immune landscape that improves the efficacy of cancer immunotherapy. We introduced mass cytometry to determine the personalized immune checkpoint status in bone marrow and peripheral blood samples from 3 patients with multiple myeloma, amyloid light-chain amyloidosis, and solitary bone plasmacytoma and 1 non-hematologic malignancy patient. The expression of 18 immune regulatory receptors and ligands on 17 defined cell populations was simultaneously examined. By single-cell analyses, we identified the $\mathrm{T}$ cell clusters that serve as immunosuppressive signal source and revealed integrated immune checkpoint axes of individuals, thereby providing multiple potential immunotherapeutic targets, including programmed cell death protein 1 (PD-1), inducible co-stimulator (ICOS), and cluster of differentiation 28 (CD28), for each patient. Distinguishing the cell populations that function as providers and receivers of the immune checkpoint signals demonstrated a distinct cross-interaction network of immunomodulatory signals in individuals. These in-depth personalized data
\end{abstract}

Correspondence to: Professor Jinheng Wang, Affiliated Cancer Hospital \& Institute of Guangzhou Medical University, Guangzhou Municipal and Guangdong Provincial Key Laboratory of Protein Modification and Degradation, School of Basic Medical Sciences, State Key Laboratory of Respiratory Disease, Guangzhou Medical University, Guangzhou, Guangdong 510095, P.R. China

E-mail: wangjh89@gzhmu.edu.cn

*Contributed equally

Key words: immune checkpoint atlas, plasma cell dyscrasias, single-cell analysis, mass cytometry demonstrate mass cytometry as a powerful innovation to discover the systematical immune status in the primary and peripheral tumor microenvironment.

\section{Introduction}

Emerging single-cell technologies, including single-cell DNA/RNA sequencing and mass cytometry, enable characterization of the extensive degree of heterogeneity in the cell pool by simultaneously quantifying a large number of parameters in single cells (1-3). Single-cell sequencing allows simultaneous analysis of the genes and transcript expression levels in individual cells at the DNA or RNA level (4). However, it is limited by an incapability of quantifying proteins that perform dominant functions within cells and thus cannot precisely identify the bioactive status in single cells or certain cell populations via surface marker-guided phenotyping. One of the traditional techniques used to determine cell subsets from a heterogeneous cell population is fluorescence-activated cell sorting (FACS), which is restricted by the number of detection channels (generally <15) and cumbersome compensation due to spectral spillover. In contrast, the newest form of mass cytometry is capable of simultaneously measuring more than 40 parameters in thousands to millions of individual cells with minimal/no compensation $(5,6)$. Cytometry with increased parameters presents an unprecedented opportunity to measure more membrane or intercellular targets and identify markers, therefore revealing high-dimensional details at the single-cell resolution in well-defined phenotypic populations. In recent years, this powerful innovation has already become widely employed to obtain a detailed understanding of complex processes in cellular development $(7,8)$, proliferation $(9,10)$, and differentiation $(11,12)$ and disease progression $(13,14)$.

Novel immunotherapeutic approaches, such as immune checkpoint blockade and chimeric antigen receptor $\mathrm{T}$ cell therapy, which mainly function to reactivate endogenous antitumor $\mathrm{T}$ cells or construct specific antitumor $\mathrm{T}$ cells, expand the options for effective cancer therapy $(15,16)$. Immune checkpoints represent a series of co-stimulatory and co-inhibitory molecules expressed on $\mathrm{T}$ cells and other 
leukocytes that regulate $\mathrm{T}$ lymphocyte activation and effector functions $(17,18)$. These immune regulatory checkpoints play critical roles in the maintenance of self-tolerance and immune homeostasis under normal physiological conditions; however, cancer cells co-opt these checkpoints to escape immune attack $(19,20)$. Nevertheless, blocking inhibitory receptors can enlist and strengthen the immune system to attack tumors and has achieved clinical success in treating many tumor types, even metastatic and chemo-resistant cancer (21-24). Targeting cytotoxic T lymphocyte-associated protein 4 (CTLA-4) and the interaction between programmed cell death 1 (PD-1) and PD ligand 1 (PD-L1) are the most prominent immune checkpoint blockade strategies in the clinic (25-28). However, these immunotherapies fail to overcome cancer in a significant proportion of patients, largely due to inter-individual heterogeneity of the onco-immune phenotype in the primary tumor microenvironment and the fact that signals inducing $\mathrm{T}$ cell exhaustion and dysfunction are not fully and sustainably blocked $(21,29)$. Accordingly, it is necessary to determine more potential immune biomarkers with clinical efficacy that can facilitate the selection of immune checkpoint blocking targets or strategies to improve immunotherapies. After analyzing mass cytometry data collected from 73 patients with clear cell renal cell carcinoma, Chevrier et al discovered heterogeneous levels of co-inhibitory receptors, including CTLA-4 and T cell immunoglobulin mucin domain 3 (Tim-3) and absent lymphocyte-activation gene 3 (LAG3) in tumor-infiltrating $\mathrm{PD}-1^{+}$cells (30). Inspiringly, mass cytometry-based single-cell analysis was utilized to predict the response to PD-1 blockade in patients with stage IV melanoma and demonstrated that responders had higher expression of HLA-DR, CTLA-4, CD56 and CD45RO and lower expression of CD3, CD27 and CD28 in peripheral blood (PB) mononuclear cells than non-responders before therapy (31). These latest studies emphasize the variability of immune checkpoints and bring the clinical application of mass cytometry-based in-depth analysis closer to reality.

Plasma cell dyscrasias (PCD), also termed plasma cell disorders, are an orchestrated spectrum of heterogeneous diseases, such as multiple myeloma (MM), amyloid light-chain (AL) amyloidosis, and solitary bone plasmacytoma (SBP), characterized by a malignant clonal proliferation of plasma cells (32). With the widespread application of immune checkpoint blockade for cancer therapy, this strategy has also been applied to induce and reinforce anti-myeloma immunity. However, a phase $1 \mathrm{~b}$ study of a single PD-1 antibody for $\mathrm{MM}$ treatment showed no significant disease regression, although MM cells highly express PD-L1 (33-36), implicating that single-agent therapy is insufficient to induce clinically meaningful anti-MM immunity. In addition, little information is known about the immune checkpoints in other PCD patients due to restrictions on the methods for analyzing multiple parameters in various cell types. Considering the complex nature of immune dysfunction in the tumor microenvironment of MM or other form of PCD, it is vital to obtain a comprehensive image of the immunologic milieu, which will drive the discovery of more precise and comprehensive blockade targets to finally reverse tumor-mediated immune suppression and expand malignant plasma cell-reactive T cells.
In the present study, we introduced mass cytometry technology to map the immune microenvironment of 3 PCD patients and 1 non-PCD patient at a single-cell resolution. To integrally understand immune checkpoint status in immune cells, an antibody panel was specifically designed to assess 13 immune cell markers and 18 immunomodulatory receptors and ligands. As the sample source or processing methods may impact the biology of immune cells, we collected samples from both the bone marrow (BM) and $\mathrm{PB}$ and processed these samples with direct fixation or fixation after mononuclear cell (MC) isolation. Our study supports the use of mass cytometry technology as a novel tool for determining personalized immune information and expands the view of the specific providers and receivers of immune checkpoint axes in PCD patients.

\section{Materials and methods}

Human specimens. Peripheral blood (PB) and bone marrow (BM) samples were concurrently collected from patients undergoing diagnosis between October 2017 and December 2017 at the Third Affiliated Hospital of Sun Yat-sen University after obtaining patient informed consent. All protocols were reviewed and approved by the Third Affiliated Hospital of Sun Yat-sen University Ethics Committee. The patient details are listed in Table SI. Samples were collected from 3 patients with PCD and 1 patient who was diagnosed without any hematological malignancy (NHM).

Sample collection and cell fixation. PB and BM samples were collected from the patients into sodium heparin tubes. PB or BM (1-2 ml) samples were directly fixed with 1X Fix I Buffer (cat.no. 201065, Fluidigm) for $10 \mathrm{~min}$ at room temperature (RT); thereafter, red blood cells were removed using red blood lysis buffer. Bone marrow mononuclear cells (BMMCs) or peripheral blood mononuclear cells (PBMCs) were collected from freshly collected samples via a Lymphoprep (cat. no.07851,STEMCELL Technologies) gradient and then fixed with 1X Fix I Buffer for $10 \mathrm{~min}$ at RT. Fixed cells were resuspended in cell staining buffer (CSB) [0.5\% bovine serum albumin (BSA) and $0.02 \%$ sodium azide in Dulbecco's phosphate buffered saline] with $10 \%$ DMSO and stored at $-80^{\circ} \mathrm{C}$ before use.

Antibody staining. Fixed cells $\left(1-2 \times 10^{6}\right)$ were washed twice with CSB and incubated with Human Fc Receptor Binding Inhibitor Antibody (cat. no. 85-14-9161-73, eBioscience) for $10 \mathrm{~min}$ at RT. Samples were initially stained with biotin anti-human OX40L (cat. no. 326306, Biolegend) and APC anti-human ICOSL (cat. no. 309407, Biolgend) for $30 \mathrm{~min}$ at RT and washed twice with CSB. Thereafter, samples were stained with 29 metal isotope-labeled antibodies against 29 human surface molecules and 2 metal isotope-labeled antibodies against biotin or APC (Table SII) for $30 \mathrm{~min}$ at RT. After washing with CSB twice, the cells were resuspended in $1 \mathrm{ml}$ of nucleic acid Ir-Intercalator (125 nM, cat. no. 201192A, Fluidigm) overnight at $4^{\circ} \mathrm{C}$. The cells were then washed once in CSB and three times in ultrapure water; thereafter, the cells were resuspended in ultrapure water containing $15 \% \mathrm{EQ}$ Four Element Calibration Beads (cat. no. 201078, Fluidigm) and acquired on Helios mass cytometer (Fluidigm). After 
acquisition, the data were normalized to make all samples maximally comparable using bead-based normalization in CyTOF software 6.7 (Fluidigm).

Data analysis. Debris, beads, and doublets were removed from the events and the single cell data were used for further analyses. Analysis by mass cytometry contour plots, heatmaps, viSNE maps, and SPADE tress was performed on the Cytobank platform www.cytobank.org (37). FlowJo version V10 was used for generating histogram overlays (FlowJo ${ }^{\mathrm{TM}}$ Software, v.10; Becton, Dickinson and Company).

\section{Results}

In-depth immunophenotyping of relapsed MM samples. To evaluate the immune status of individual patients, BM and PB samples were collected at the time of BM biopsy for diagnosis and fixed directly (Q-FIX) or fixed after MC isolation (G-FIX; Fig. 1A). We stained cells with an antibody panel containing 31 antibodies against 13 immune cell markers and $18 \mathrm{immu}-$ nomodulatory molecules (Fig. 1A), and single-cell data were acquired using mass cytometry. Multiple methods, including gating, heatmapping, viSNE, and spanning-tree progression analysis of density-normalized events (SPADE) (12) were performed for in-depth single-cell analysis.

Based on standardized immunophenotyping for human immunology (38), 17 cell populations (P1-P17) were identified (Fig. 1B). The frequency of each population in each sample obtained from a relapsed MM patient with low malignant plasma (MM) cells which may be caused by unavoidable interfusion of PB during marrow extraction, was analyzed. Because malignant plasma cells are mainly localized in the $\mathrm{BM}$, the proportion of plasma cells in the BM (G-FIX) sample (1\%) was larger than that in the PB (G-FIX) sample (0.04\%), whereas no significant differences in the frequency of the other populations except for $\mathrm{P} 7$ were observed between them (Fig. 1C). Although the percentage of MM cells is low, this patient still was diagnosed with relapsed MM based on diagnostic history and the other examinations. We analyzed the distribution of gated immune cells using a viSNE map to visualize high-dimensional data in two dimensions, and multiple masses representing differenT cell populations were clearly displayed after 13 marker channel-based viSNE analysis. The expression of defining markers shown on the viSNE map was identical to the phenotypes of the gated cell populations (Fig. 1D). Expression levels of the defining markers in defined cell populations were similar between Q-FIX and G-FIX samples (Fig. 1E), suggesting that these two process methods are reliable for population analysis.

Immune checkpoint landscape in the relapsed MM patient. Expression profiles containing 18 immune checkpoint molecules of the 17 cell populations were visualized in heatmaps (Fig. 2A), showing similar expression pattern between the BM and PB samples. For instance, monocytes (P10 and P11) and myeloid-derived suppressor cells (MDSCs) (P12) in the BM (Q-FIX) sample expressed a lower level of galectin-9 (GAL9) than those in the PB (Q-FIX) sample, and lineage ${ }^{-}$D $34^{+}$cells (P14) in the PB (Q-FIX) sample expressed a higher level of programmed death ligand 1 (PD-L1) and PD-L2 than those in the BM (Q-FIX) sample (Fig. 2A). We next used viSNE to assess the heterogeneity of these immunomodulatory molecules at a single-cell resolution (Figs. 2B and S1A). viSNE maps showed detailed distribution of these molecules and revealed more small cell subsets hiding in the cell populations, such as $\mathrm{CD}^{+}$or $\mathrm{CD}^{+} \mathrm{T}$ cell subsets highly expressing PD-1 or CD28. Because immunotherapy is mainly intended to rescue functional $\mathrm{T}$ cells, we next determined the frequency of cells expressing immune checkpoint receptors in the $\mathrm{T}$ cell subpopulations (Fig. 2C). The frequencies of $\mathrm{PD}-1^{+}$cells in the $\mathrm{BM} \mathrm{CD} 4^{+}, \mathrm{CD}^{+}$and double-positive (DP) $\mathrm{T}$ clusters were 29,16 and $14 \%$ on average, respectively, and they were 20,9 and $5 \%$ in the PB samples, whereas they were only 0.9 and $0.6 \%$ in BM and PB non-T cells, respectively. Inducible T-cell costimulator (ICOS) ${ }^{+}$cells accounted for $36 \%, 10$ and 42 of $\mathrm{BM} \mathrm{CD} 4^{+}, \mathrm{CD}^{+}$, and double-positive (DP) $\mathrm{T}$ cells, respectively, and for 25,6 , and 30 of $\mathrm{PB} \mathrm{CD} 4^{+}, \mathrm{CD}^{+}$, and $\mathrm{DP} \mathrm{T}$ cells, respectively. In total, 53-66\% of $\mathrm{CD}^{+} \mathrm{T}$ cells, $24-21 \%$ of $\mathrm{CD}^{+} \mathrm{T}$ cells, and $80-95 \%$ of DP $\mathrm{T}$ cells were positive for $\mathrm{CD} 28$ expression. A low frequency $(<8 \%)$ of CTLA-4-expressing $\mathrm{CD}^{+}{ }^{+}$and $\mathrm{CD} 8^{+} \mathrm{T}$ cells was observed in both the BM and PB samples. To exhaustively reveal $\mathrm{T}$ cell clusters with immunologic differences, we narrowed down the population using SPADE analysis (Figs. 2D and S1B). Increasing minor $\mathrm{T}$ cell subsets were clarified, such as a cluster with the highest PD-1 expression in $0.17 \%$ of $\mathrm{CD}^{+}$, $0.12 \%$ of $\mathrm{CD}^{+}$, and $9.7 \%$ of DP T cells that also expressed high levels of ICOS, CD28, human leukocyte antigen-DR isotype (HLA-DR), and CD38. When comparing the BM and PB T cells using viSNE, several small differences were detected in the combined viSNE map (Fig. S2A), such as $\mathrm{BM}$ PD-1 ${ }^{+} \mathrm{T}$ cells showing higher PD-1 expression than PB PD $-1^{+} T$ cells (Fig. S2B), indicating that the immune status of $\mathrm{T}$ cells in $\mathrm{BM}$ is different from that in PB.

Identification of immunomodulatory ligand providers in the relapsed MM patient. CD38 and HLA-DR together have proven to be useful as biomarkers for tracking activated $\mathrm{T}$ cells $(30,38)$. Thus, we employed these two markers to reveal the activation status of $\mathrm{T}$ cells in the MM patient. Activated (HLA-DR ${ }^{+} \mathrm{CD} 38^{+}$) cells accounted for 37-44, 50-60, 14-38, and $19-51 \%$ of $\mathrm{CD}^{+}, \mathrm{CD}^{+}$, double-positive (DP), and double-negative (DN) T cells, respectively (Fig. 3A). Analysis of immunomodulatory molecules in these $\mathrm{T}$ cell clusters showed that activated $\mathrm{T}$ cells tended to express higher levels of PD-1 and ICOS than the other $3 \mathrm{~T}$ cell subsets. Interestingly, activated $\mathrm{CD} 8^{+} \mathrm{T}$ (T5) cells barely expressed $\mathrm{CD} 28$, which provides co-stimulatory signals required for $\mathrm{T}$ cell activation and survival (Fig. 3B). MalignanT cells usually express high levels of ligands that recognize the immunomodulatory receptors on $T$ cells to create an immunosuppressive microenvironment. In addition, ligands matched with PD-1, ICOS, and CD28 were offered by plasma cells, B cells, monocytes, and MDSCs in the BM and PB (Figs. 3C and S2C and D). Plasma cells were identified as the significant source of ligands in the BM because 92, 92 and 97\% of them expressed PD-L1, PD-L2, and ICOSL, respectively (Fig. 3D).

Immune landscape in a non-hematologic malignancy (NHM) patient. To confirm the reliability of mass cytometry-based 
A

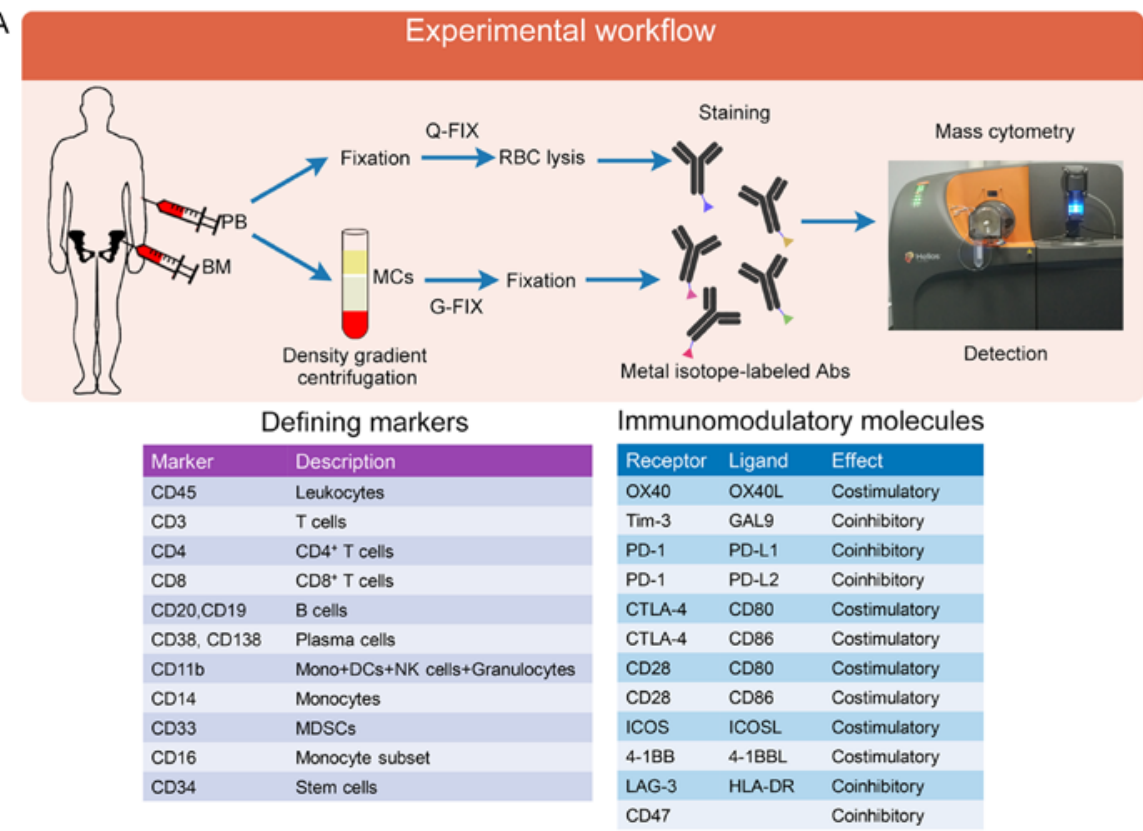

B

\begin{tabular}{|c|c|c|}
\hline ID & Phenotype & Name \\
\hline P1 & $\mathrm{CD} 38^{\circ}=\mathrm{CD} 45 / \mathrm{mm}$ & CD 38 " cells \\
\hline P2 & $\mathrm{CD} 38^{*} \mathrm{CD} 138^{*}$ & $\mathrm{CD} 38^{*+} \mathrm{CD} 138^{*}$ plasma cells \\
\hline P3 & $\mathrm{CD}_{4} 5^{\circ} \mathrm{CD} 3^{+} \mathrm{CD} 4{ }^{-} \mathrm{CD} 8^{*}$ & CD8* $T$ cells \\
\hline P4 & $\mathrm{CD}_{4} 5^{\circ} \mathrm{CD} 3^{+} \mathrm{CD} 8 \mathrm{CD}^{*} 4^{+}$ & CD4* T cells \\
\hline P5 & $\mathrm{CD} 45^{+} \mathrm{CD} 3^{+} \mathrm{CD} 4{ }^{-} \mathrm{CD} 8{ }^{-} \mathrm{CD} 16^{*}$ & DN CD16 $6^{*} T$ cells \\
\hline P6 & $\mathrm{CD} 5^{\circ} \mathrm{CD} 3^{+} \mathrm{CD} 4 \mathrm{CD}^{-\mathrm{CD}} 16^{-}$ & DN CD16-T cells \\
\hline P7 & $\mathrm{CD} 3{ }^{-} \mathrm{CD} 19^{\circ} \mathrm{CD} 20^{*}$ & CD20 $\mathrm{B}$ cells \\
\hline P8 & $\mathrm{CD} 3 \mathrm{CD}_{19}{ }^{\circ} \mathrm{CD} 20^{\circ}$ & CD20 B cells \\
\hline $\mathbf{P 9}$ & $\mathrm{CD} 3 \mathrm{CD}^{\circ} 9^{\circ} \mathrm{CD} 20^{\circ} \mathrm{CD} 38^{*}$ cells & Plasmablasts \\
\hline P10 & $\mathrm{CD}^{-\mathrm{CD} 19} \mathrm{CD}^{-} 0^{-C D} 11 \mathrm{~b}^{*} \mathrm{CD} 14^{\circ} \mathrm{CD} 16^{*}$ & Non-classical CD16* monocytes \\
\hline P11 & $\mathrm{CD}^{-\mathrm{CD} 19} \mathrm{CD}^{-} 0^{\circ} \mathrm{CD} 11 \mathrm{~b}^{*} \mathrm{CD} 14^{\circ} \mathrm{CD} 16^{-}$ & Classical monocytes \\
\hline P12 & 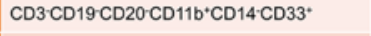 & MDSCs \\
\hline P13 & 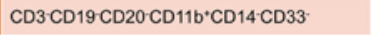 & Granulocytes+DCs+NK(GDN) cells \\
\hline P14 & $\mathrm{CD}^{-} \mathrm{CD} 19 \mathrm{C}^{-C D} 20^{-} \mathrm{CD} 11 \mathrm{~b}^{-} \mathrm{CD} 14 \mathrm{CD}^{-} 4^{*}$ & Lineage CD $34^{\circ}$ cells \\
\hline P15 & $\mathrm{CD}^{-} \mathrm{CD} 19 \mathrm{CD}^{-} 0^{-} \mathrm{CD} 11 \mathrm{~b}-\mathrm{CD} 14 \mathrm{CD}^{-} \mathrm{C} \mathrm{CD}^{-} 5^{\circ}$ & Rest of $\mathrm{CD} 45^{*}\left(\mathrm{r}-\mathrm{CD} 45^{\circ}\right)$ cells \\
\hline P16 & 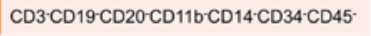 & Rest of $\mathrm{CD} 45-\left(r-\mathrm{CD} 45^{-}\right)$cells \\
\hline P17 & $\mathrm{CD} 45^{\circ} \mathrm{CD} 3^{+} \mathrm{CD} 4^{*} \mathrm{CD} 8^{*}$ & DP T cells \\
\hline
\end{tabular}

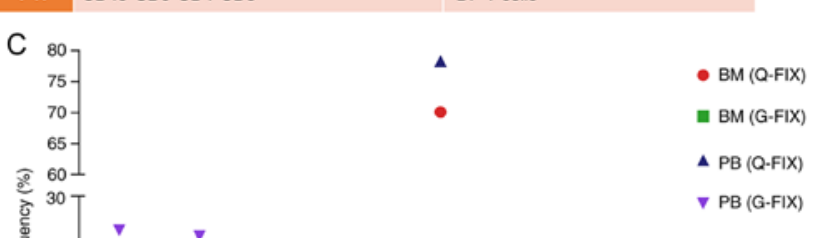

Figure 1. Identification of the immune populations in PB and BM cells of a relapsed MM patient. (A) Experimental approach and single-cell analysis methods used in this study and markers used to define cell populations and onco-immune phenotypes. (B) Phenotypes of the gated populations. (C) Frequency of immune lineages for each sample collected from the relapsed MM patient's PB or BM. 

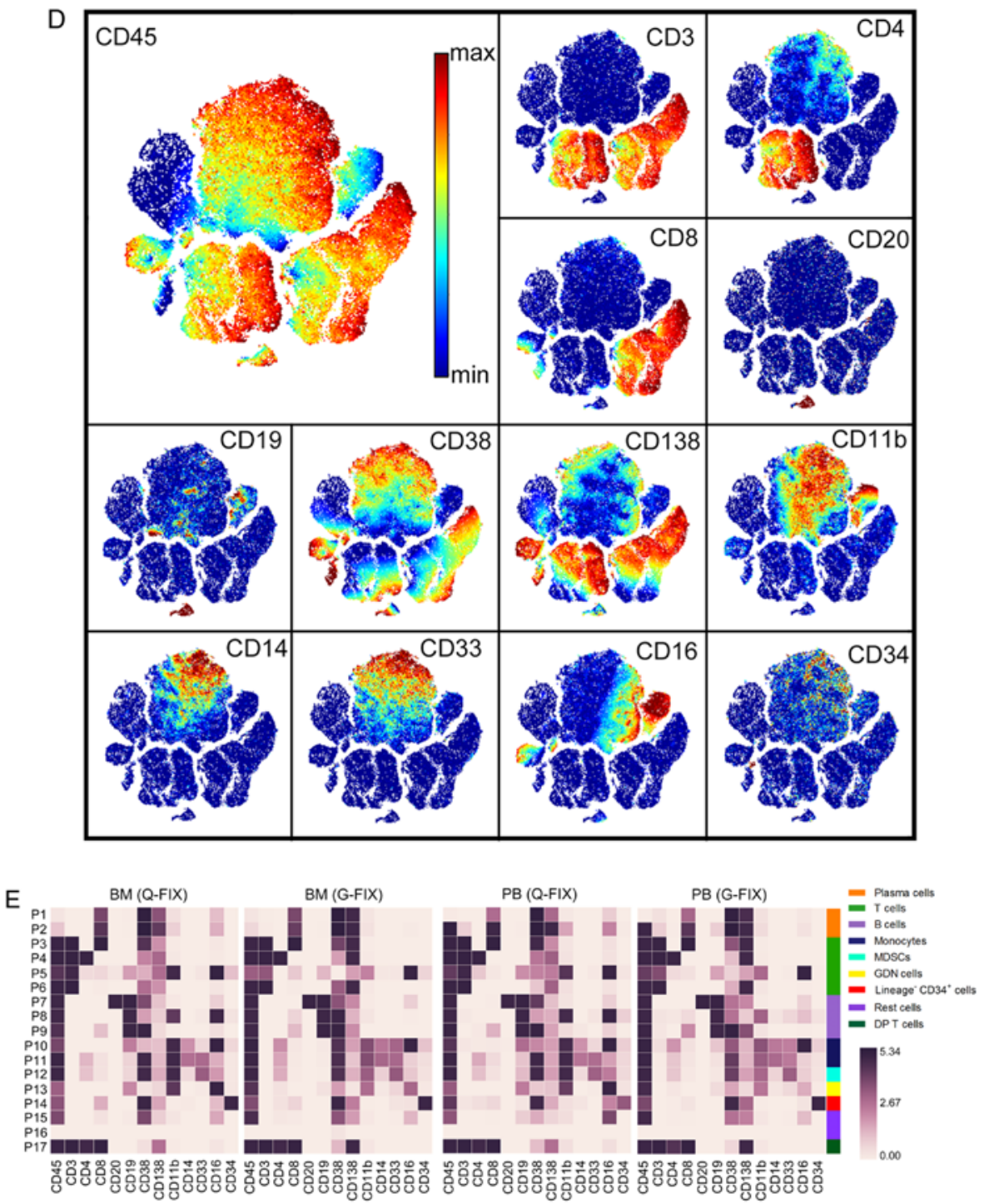

Figure 1. Continued. (D) viSNE maps displaying BM (G-FIX) cells from the relapsed MM patient and colored by the normalized expression of the indicated markers. (E) Heatmaps showing the normalized median expression of 13 markers in all cell populations. Cell types are indicated by color. MM, multiple myeloma; PB, peripheral blood; BM, bone marrow; MCs, mononuclear cells; RBC, red blood cell; Abs, antibodies; Mono, monocytes; DCs, dendritic cells; NK, natural killer; MDSCs, myeloid-derived suppressor cells; DP T cells, double-positive T cells; Q-FIX, fixed directly; G-FIX, fixed after MC isolation.

immune analysis, we next determined the immune landscape in an NHM patient. This patient was initially suspected with $\mathrm{MM}$ and later diagnosed with an abnormal hemogram induced by medicine. Plasma cells accounted for 0.9 and $0 \%$ of all BM and PB cells, respectively, and these are accordant with clinical examination results of the bone marrow sample determined using flow cytometry. The proportions of the other populations were examined and are presented (Fig. 4A). Next, full-scale expression levels of defining markers and immunomodulatory molecules were determined by heatmapping and viSNE map (Figs. 4B and S3A and B), showing different immune phenotypes from those in the MM patient. viSNE map showed the distribution of all the molecules and revealed $\mathrm{PD}-1^{+}, \mathrm{CD} 28^{+}$, and $\mathrm{ICOS}^{+}$cells in the $\mathrm{BM} \mathrm{T}$ cell populations (Fig. 4C). When we analyzed BM and PB T cells together, we observed that PD- $1^{+} \mathrm{T}$ cells in the BM showed higher PD-1 signals than those in the PB. Subtle distinctions between BM and PB T cells were identified in the expression of Tim-3, CTLA-4, CD8, and CD14 (Fig. S3C).
In this patient, the percentages of PD-1 $1^{+}$cells among BM $\mathrm{CD}^{+}, \mathrm{CD}^{+}$, and DN T cells on average were 12,50 , and $45 \%$, respectively, and they were 11,30 , and $17 \%$ in the PB T cell subpopulations. ICOS was expressed by $37 \%$ of $\mathrm{CD}^{+}$and $23 \%$ of $\mathrm{CD}^{+} \mathrm{T}$ cells (Fig. 4D). In all, 95-97\% of $\mathrm{CD}^{+} \mathrm{T}$ cells and $60-70 \%$ of $\mathrm{CD}^{+} \mathrm{T}$ cells expressed CD28. Less than $3 \%$ of BM or $\mathrm{PB} \mathrm{CD} 4^{+} \mathrm{T}$ cells, $28 \%$ of $\mathrm{BM} \mathrm{CD} 8^{+}$or $\mathrm{DN} \mathrm{T}$ cells, $17 \%$ of PB CD $8^{+} \mathrm{T}$ cells, and $15 \%$ of PB DN T cells, were activated (Fig. S4A), and these cells had a tendency for higher PD-1, ICOS, and CD28 expression than pre/non-activated T cells (Fig. S4B).

The main providers of ligands for receptors on T cells included MDSCs, the population containing granulocytes, dendritic, and natural killer (GDN) cells, and monocytes, and plasma cells provided minimal ligands. PD-L1 signaling, which is important for $\mathrm{T}$ cell suppression, was consistently subdued in these providers (Fig. 4E and F).

Immune landscape in an AL amyloidosis patient. We next identified the immune atlas in a patient newly diagnosed 


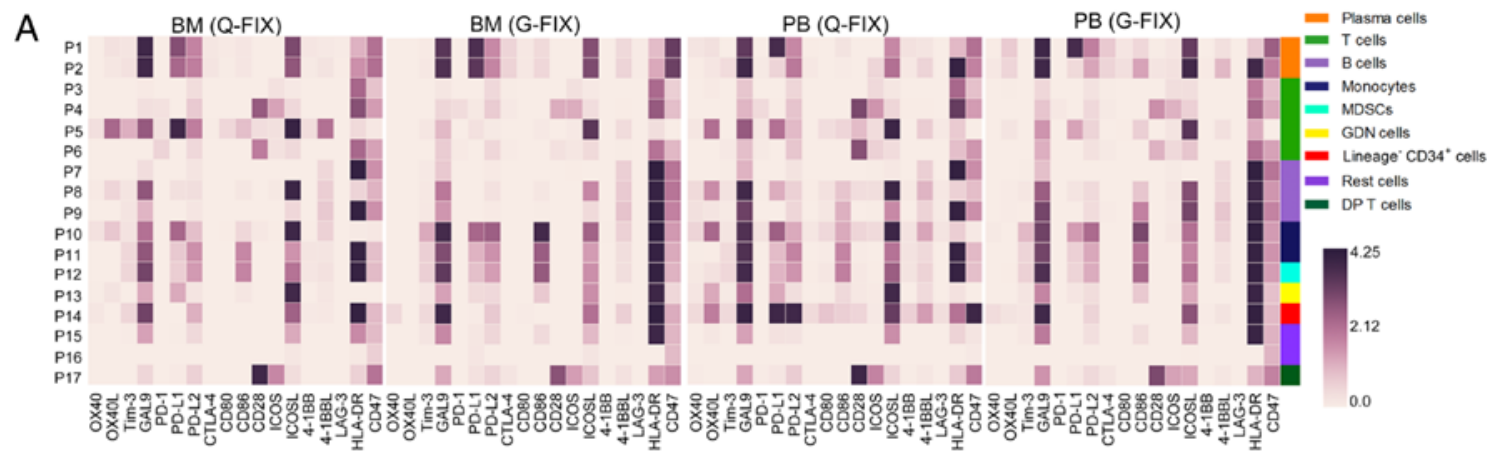

B
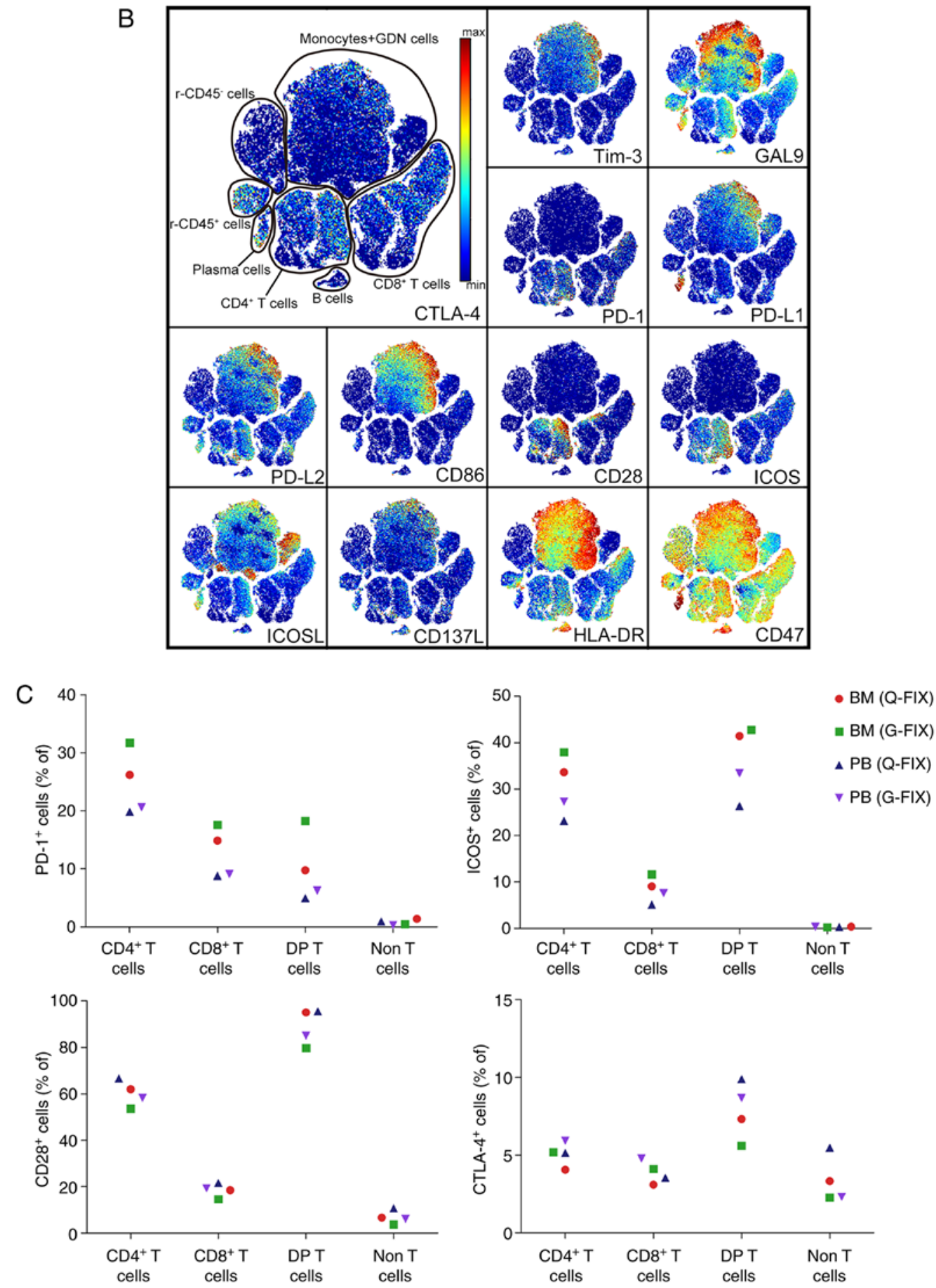

Figure 2. Onco-immune atlas in PB and BM cells of the relapsed MM patient. (A) Heatmaps showing the normalized median expression of 18 immunomodulatory molecules in all cell populations. Cell types are indicated by color. (B) viSNE maps displaying BM (G-FIX) cells from the relapsed MM patient and colored by the normalized expression of the indicated immunomodulatory molecules. (C) Frequency of PD-1 $1^{+}$, ICOS ${ }^{+}$, CD28 $8^{+}$, or CTLA- $4^{+}$cells in the indicated populations for each sample collected from the relapsed MM patient's PB or BM. 
D

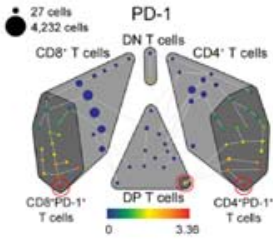

ICOS

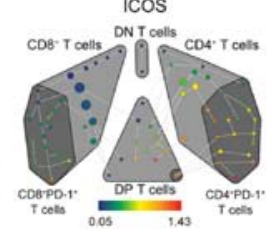

$\mathrm{CD} 28$

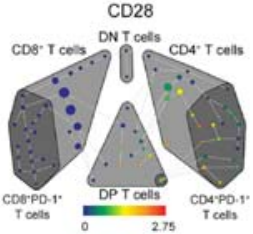

$\mathrm{CD} 38$

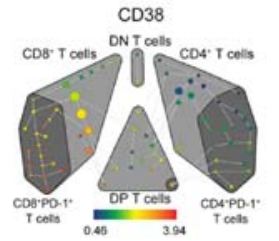

HLA-DR

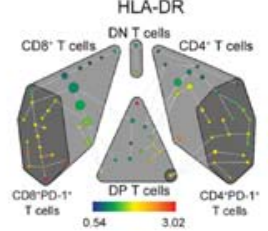

Figure 2. Continued. (D) SPADE tree describing T cell subsets and colored by the normalized expression of the indicated molecules. T cell subpopulations are gated with a grey color, and PD- $1^{+}$subsets are gated with a deep grey area. A red circle indicates a small subset that highly expresses PD-1 in the indicated T cell subpopulation. MM, multiple myeloma; PB, peripheral blood; BM, bone marrow; MDSCs, myeloid-derived suppressor cells; DP T cells, double-positive T cells; Q-FIX, fixed directly; G-FIX, fixed after MC isolation.
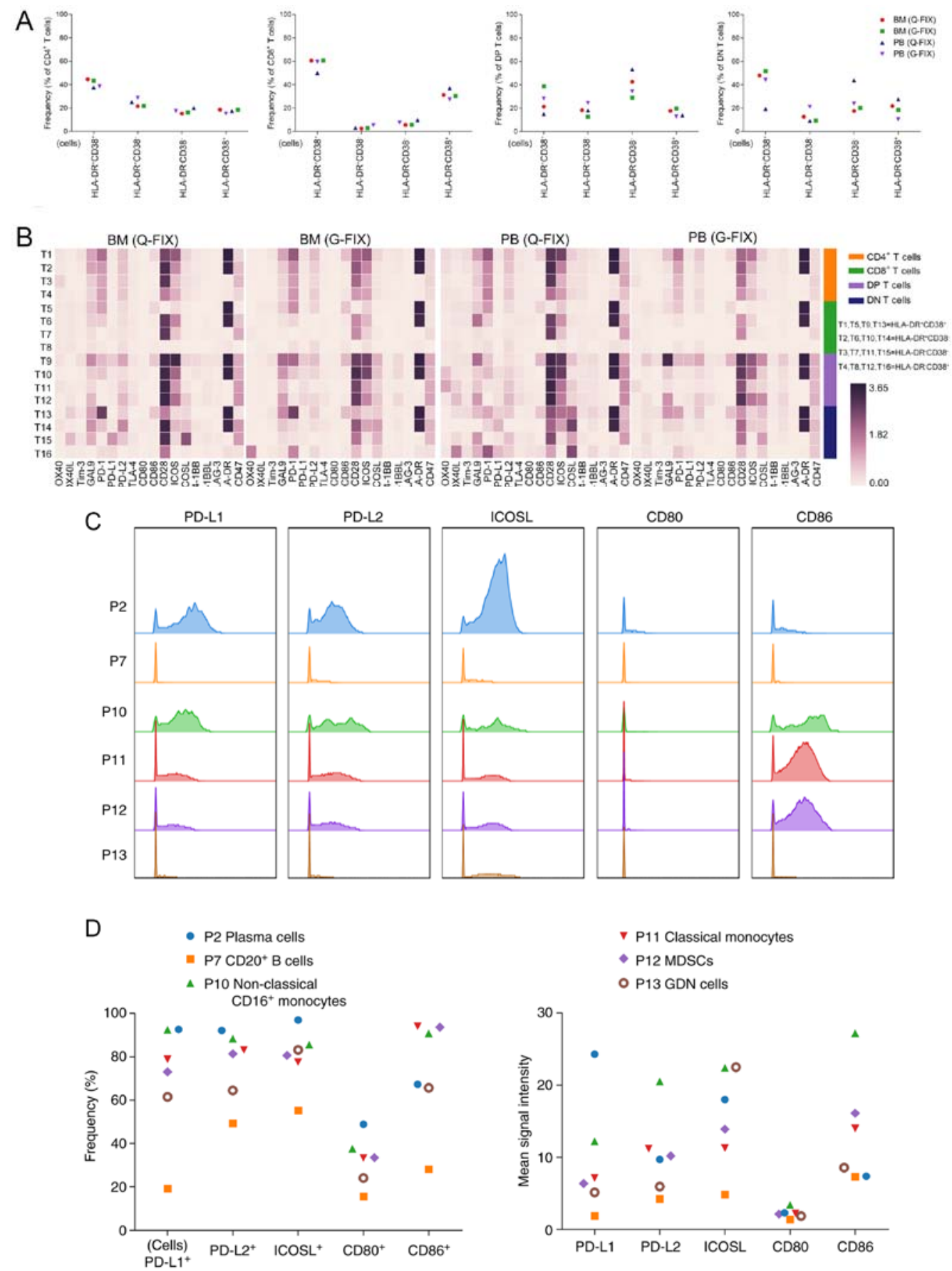

Figure 3. Defining the main providers of immunomodulatory receptors and ligands. (A) Frequency of the indicated 4 subsets in each T cell subpopulation for each sample collected from the relapsed MM patient's PB or BM. (B) Heatmaps showing the normalized mean expression of 18 immunomodulatory molecules in $16 \mathrm{~T}$ cell subsets. Four $\mathrm{T}$ cell subpopulations are indicated by color. (C) Histograms showing the expression of the indicated ligands in certain populations of BM (G-FIX) cells. (D) Frequency of the indicated subsets in certain populations (left) of BM (G-FIX) cells and the mean signal intensity of the indicated ligands (right) among the positive cells of certain populations. MM, multiple myeloma; PB, peripheral blood; BM, bone marrow; MDSCs, myeloid-derived suppressor cells; DP T cells, double-positive T cells; DN T cells, double-negative T cells; Q-FIX, fixed directly; G-FIX, fixed after MC isolation. 

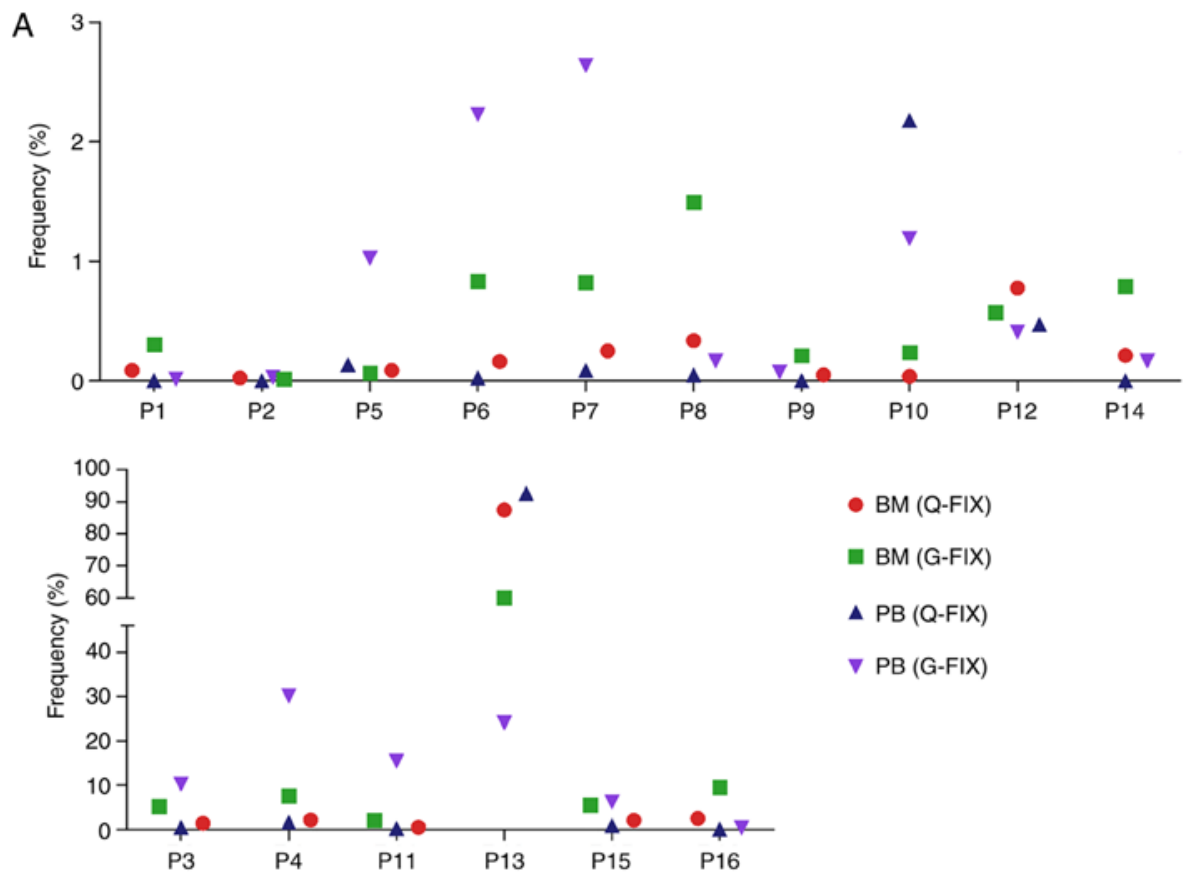

B
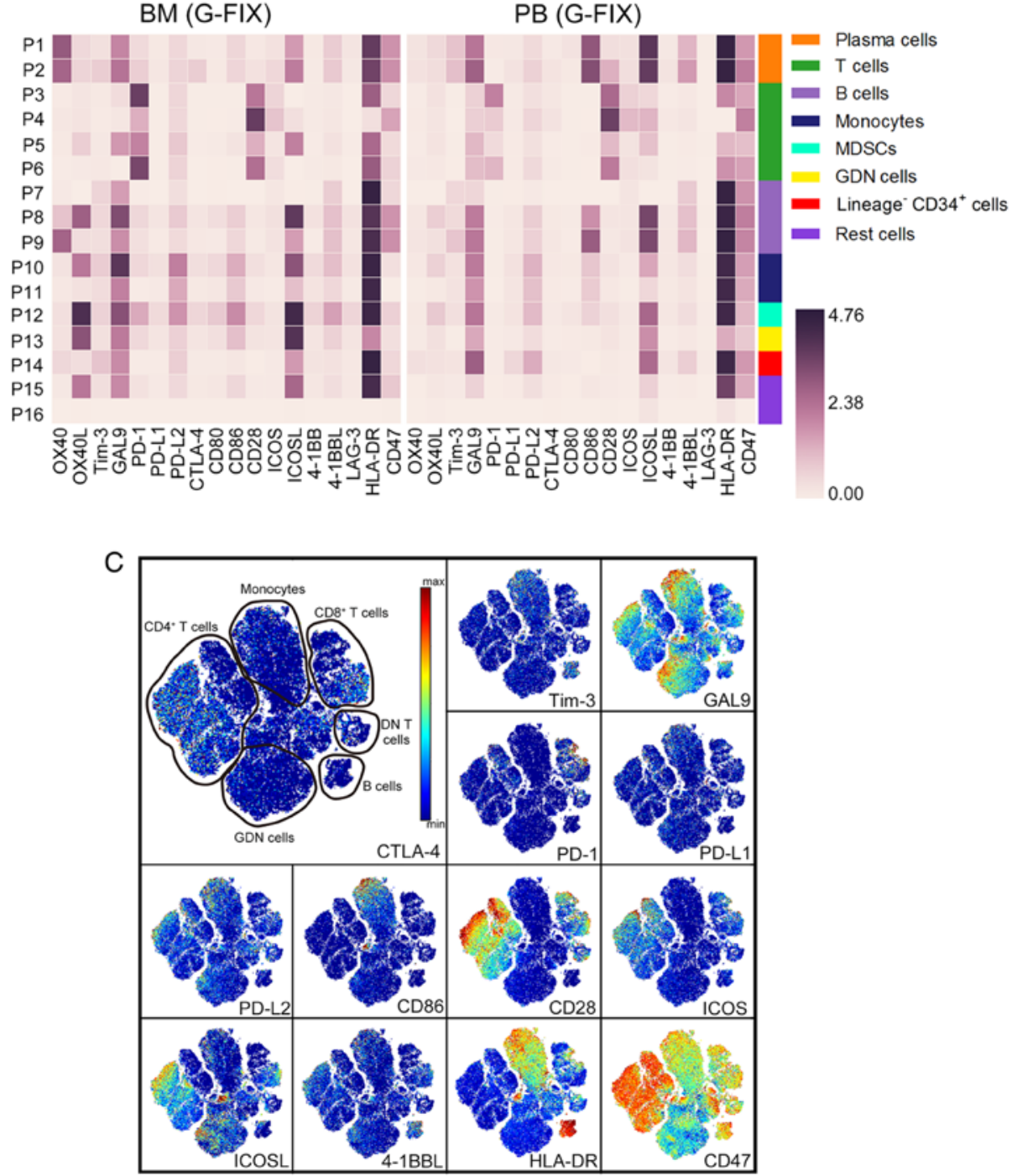

Figure 4. Onco-immune atlas in PB and BM cells of a patient without hematological malignancy. (A) Frequency of immune lineages for each sample collected from the non-hematologic malignancy (NHM) patient's PB or BM. (B) Heatmaps showing the normalized median expression of 18 immunomodulatory molecules in all cell populations. Cell types are indicated by color. (C) viSNE maps displaying BM (G-FIX) cells from the NHM patient and colored by normalized mean expression of the indicated immunomodulatory molecules. 

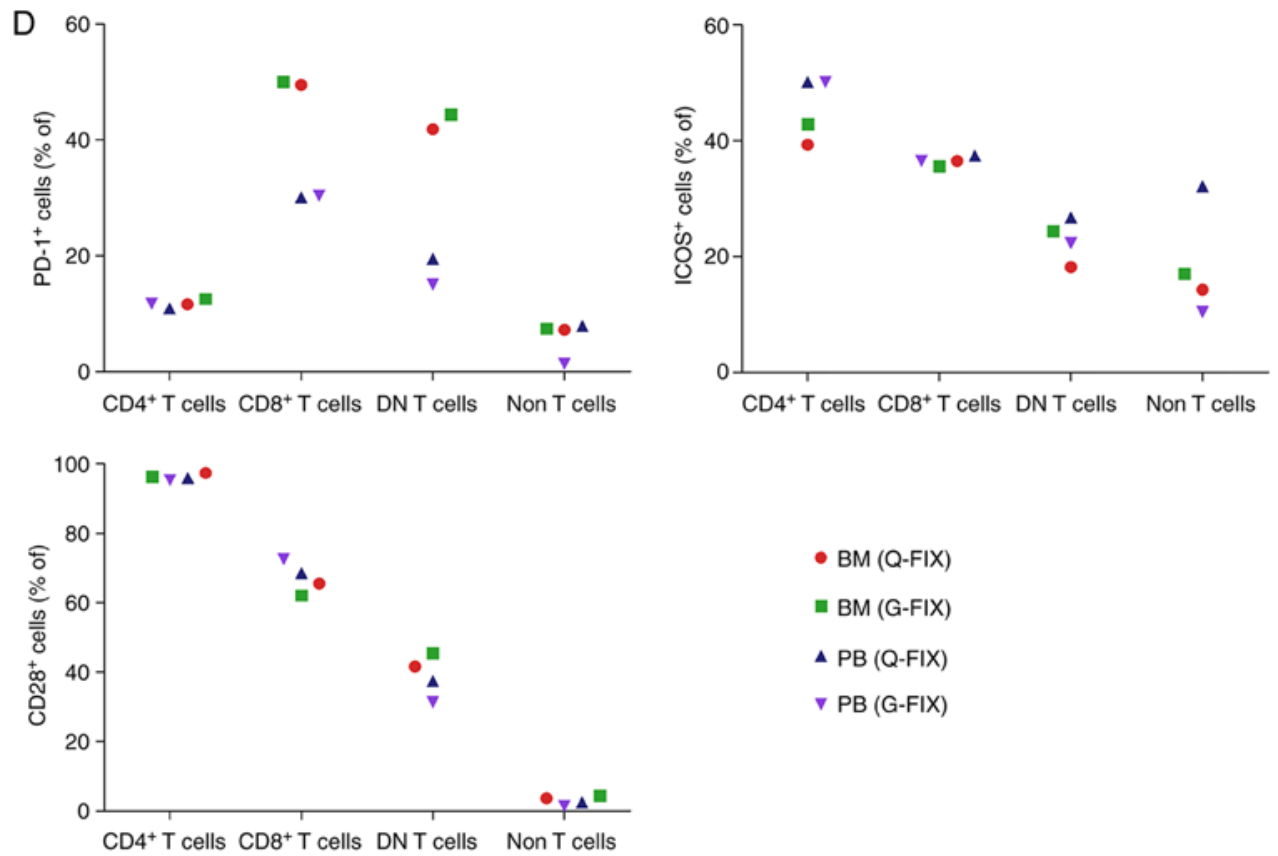

$$
\begin{aligned}
& \text { - } B M(Q-F I X) \\
& \text { - } B M(G-F I X) \\
& \text { A } P B(Q-F I X) \\
& \text { V } P B(G-F I X)
\end{aligned}
$$

$\mathrm{E}$

E PD-L1
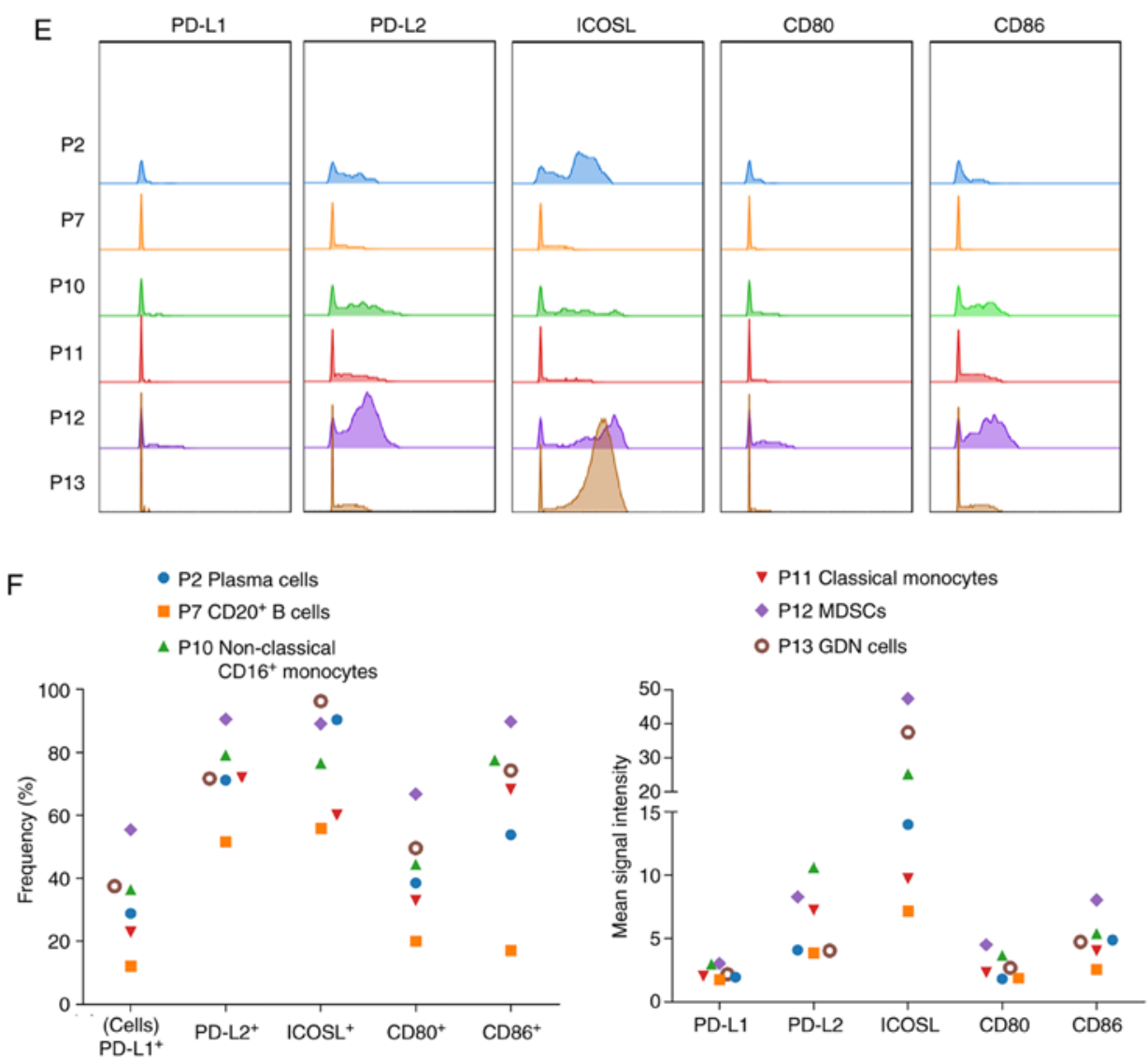

Figure 4. Continued. (D) Frequency of PD- $1^{+}$, ICOS + , or $\mathrm{CD} 28^{+}$cells in the indicated populations for each sample collected from the NHM patient's PB or BM. (E) Histograms showing the expression of the indicated ligands in certain populations of BM (G-FIX) cells. (F) Frequency of the indicated subsets in certain populations of BM (G-FIX) cells (left) and the mean signal intensity of the indicated ligands (right) among the positive cells of certain populations. PB, peripheral blood; BM, bone marrow; MDSCs, myeloid-derived suppressor cells; Q-FIX, fixed directly; G-FIX, fixed after MC isolation.

with MM-induced AL amyloidosis accompanied by renal amyloidosis. Although the proportion of plasma cells $(0.12 \%)$ was low in the BM (Fig. 5A), this patient was still diagnosed with $\mathrm{MM}$ and achieved remission after treatment with anti-MM drugs bortezomib and dexamethasone. We next used heatmapping and viSNE analysis to systematically visualize the expression of immunomodulatory molecules in all cell populations and in the defining marker-based cell distribution map (Figs. 5B and C; S5A and S5B). In total, $29-33 \%$ of $\mathrm{CD}^{+}, 32-36 \%$ of $\mathrm{CD}^{+}$, and $14-22 \%$ of DN T cells 

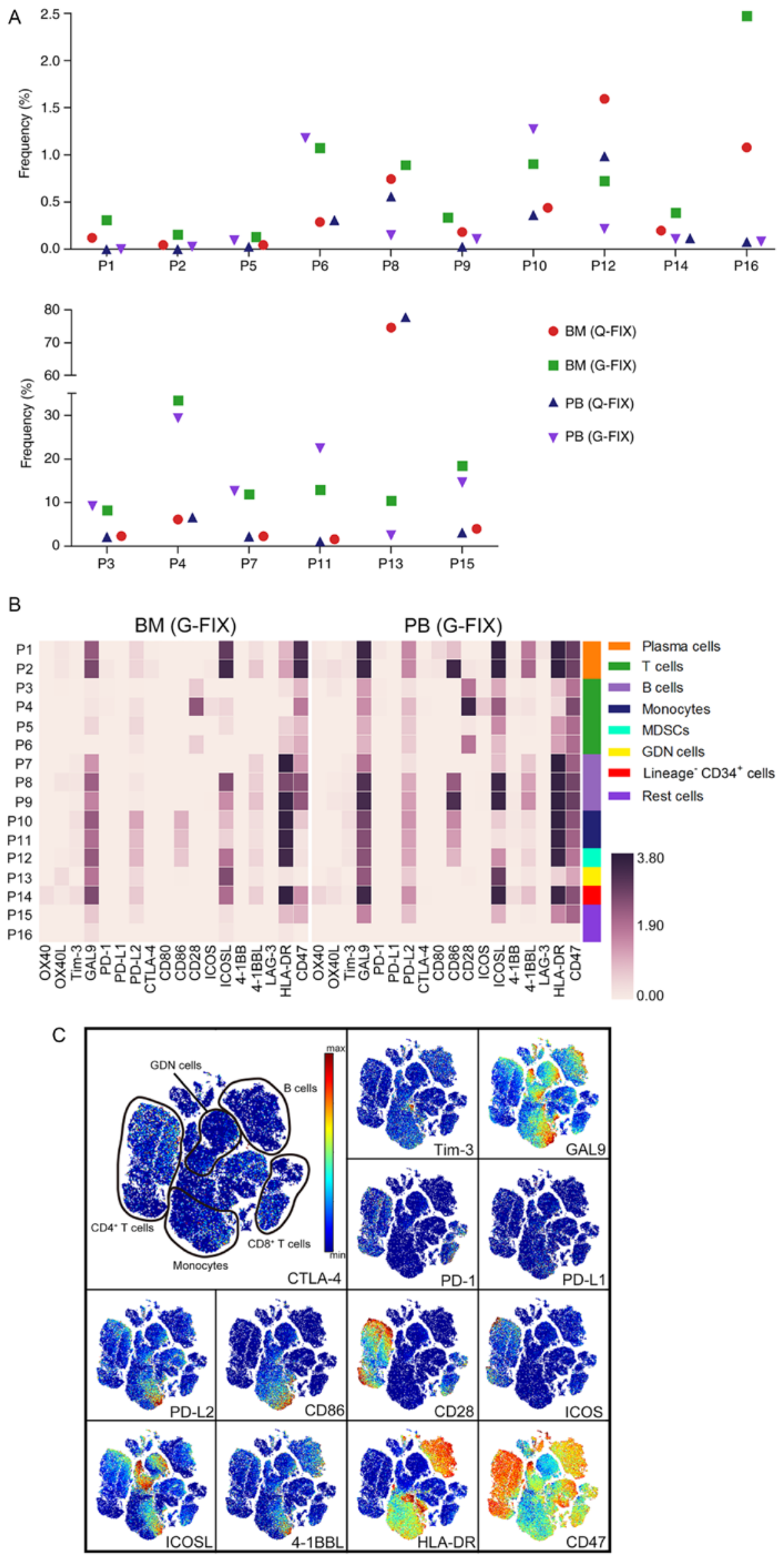

Figure 5. Onco-immune atlas in PB and BM cells of an amyloid light-chain (AL) patient. (A) Frequency of immune lineages for each sample collected from the AL patient's PB or BM. (B) Heatmaps showing the normalized mean expression of 18 immunomodulatory molecules in all cell populations. Cell types are indicated by color. (C) viSNE maps displaying PB (G-FIX) cells from the AL patient and colored by the normalized mean expression of the indicated immunomodulatory molecules. 

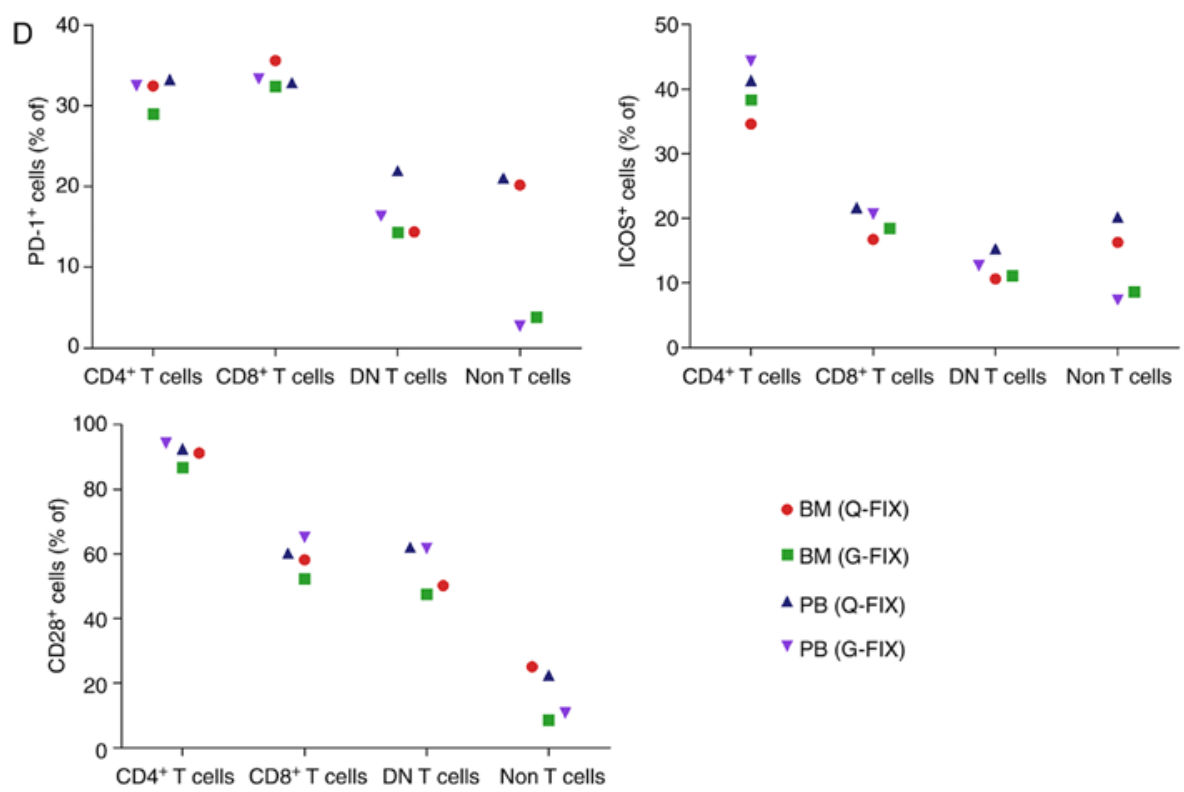

$\mathrm{E}$

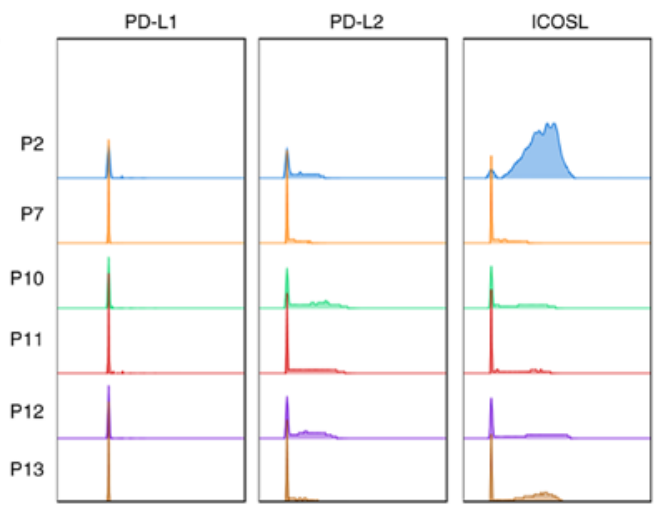

CD80
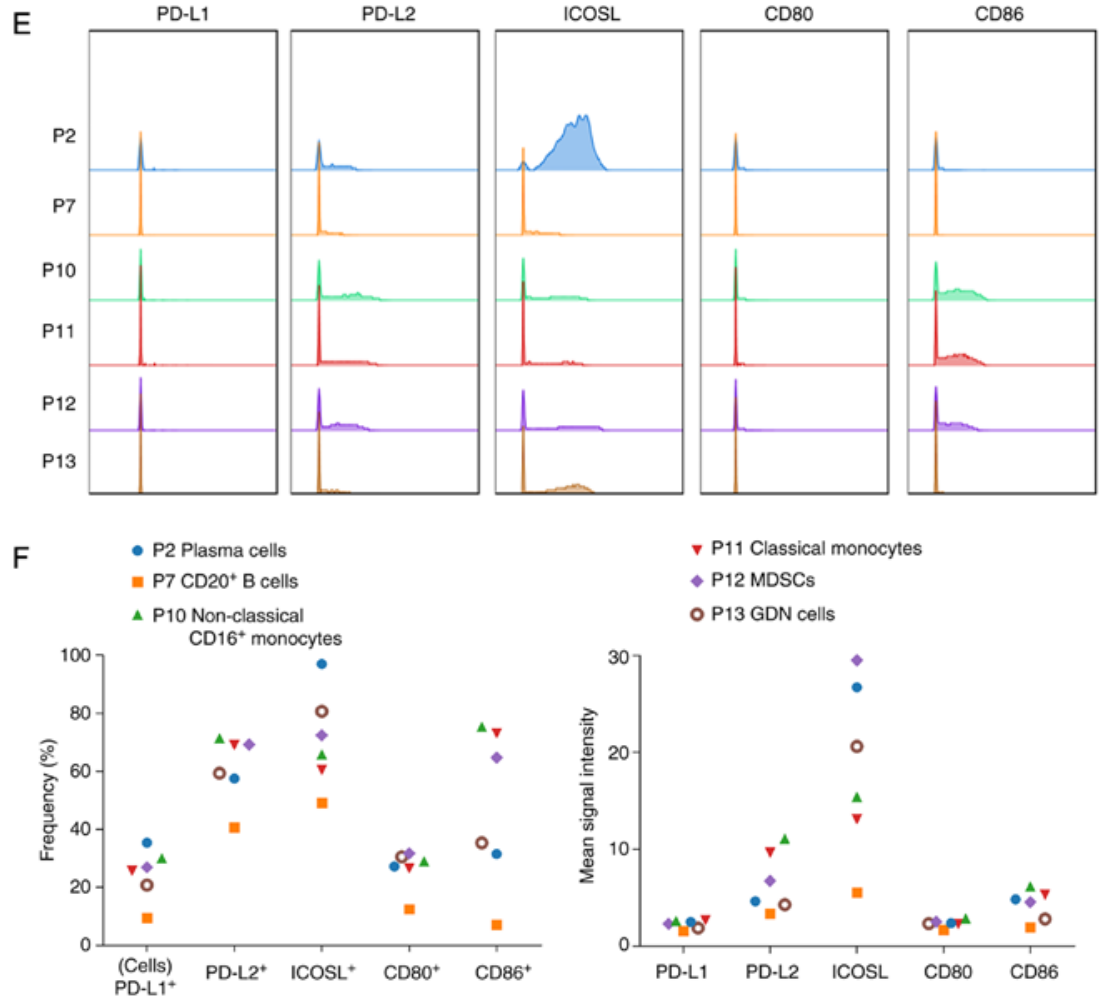

Figure 5. Continued. (D) Frequency of PD- $1^{+}, \mathrm{ICOS}^{+}$, or $\mathrm{CD} 28^{+}$cells in the indicated populations for each sample collected from the AL patient's $\mathrm{PB}$ or BM. (E) Histograms showing the expression of the indicated ligands in certain populations of BM (G-FIX) cells. (F) Frequency of the indicated subsets in certain populations of BM (G-FIX) (left) and the mean signal intensity of the indicated ligands (right) among the positive cells of certain populations. PB, peripheral blood; BM, bone marrow; MDSCs, myeloid-derived suppressor cells; Q-FIX, fixed directly; G-FIX, fixed after MC isolation.

were PD-1 positive. ICOS ${ }^{+}$cells accounted for $34-44,17-22$ and $11-15 \%$ of $\mathrm{CD}^{+}, \mathrm{CD}^{+}$, and $\mathrm{DN} \mathrm{T}$ cells, respectively. In all, $86-94 \%$ of $\mathrm{CD}^{+}, 52-65 \%$ of $\mathrm{CD}^{+}$, and $48-62 \%$ of DN T cells expressed CD28 (Fig. 5D). Less than $11 \%$ of $\mathrm{CD}^{+}, \mathrm{CD}^{+}$, and $\mathrm{DN} \mathrm{T}$ cells were confirmed to be activated (Fig. S5C), and these cells expressed higher levels of PD-1, ICOS, and CD28 than the other $3 \mathrm{~T}$ cell clusters (Fig. S5D). Ligand-expressing cells were next analyzed and plasma cells strongly expressed ICOSL, whereas barely expressed the other ligands. CD86, PD-L2, and ICOSL were more widely present in the indicated cell populations than PD-L1 and CD80 (Fig. 5E and F).

Immune atlas in a SBP patient. A 27-year-old male patient was initially admitted to the department of stomatology due to consistent swelling of the gingival mucosa and was later diagnosed with SBP, as myeloma plasma cells were detected in the gingiva but not the ilium bone marrow. The immune atlas in the $\mathrm{BM}$ and $\mathrm{PB}$ of this rare patient was analyzed by mass cytometry. Similar to the results of FACS, a low proportion of 

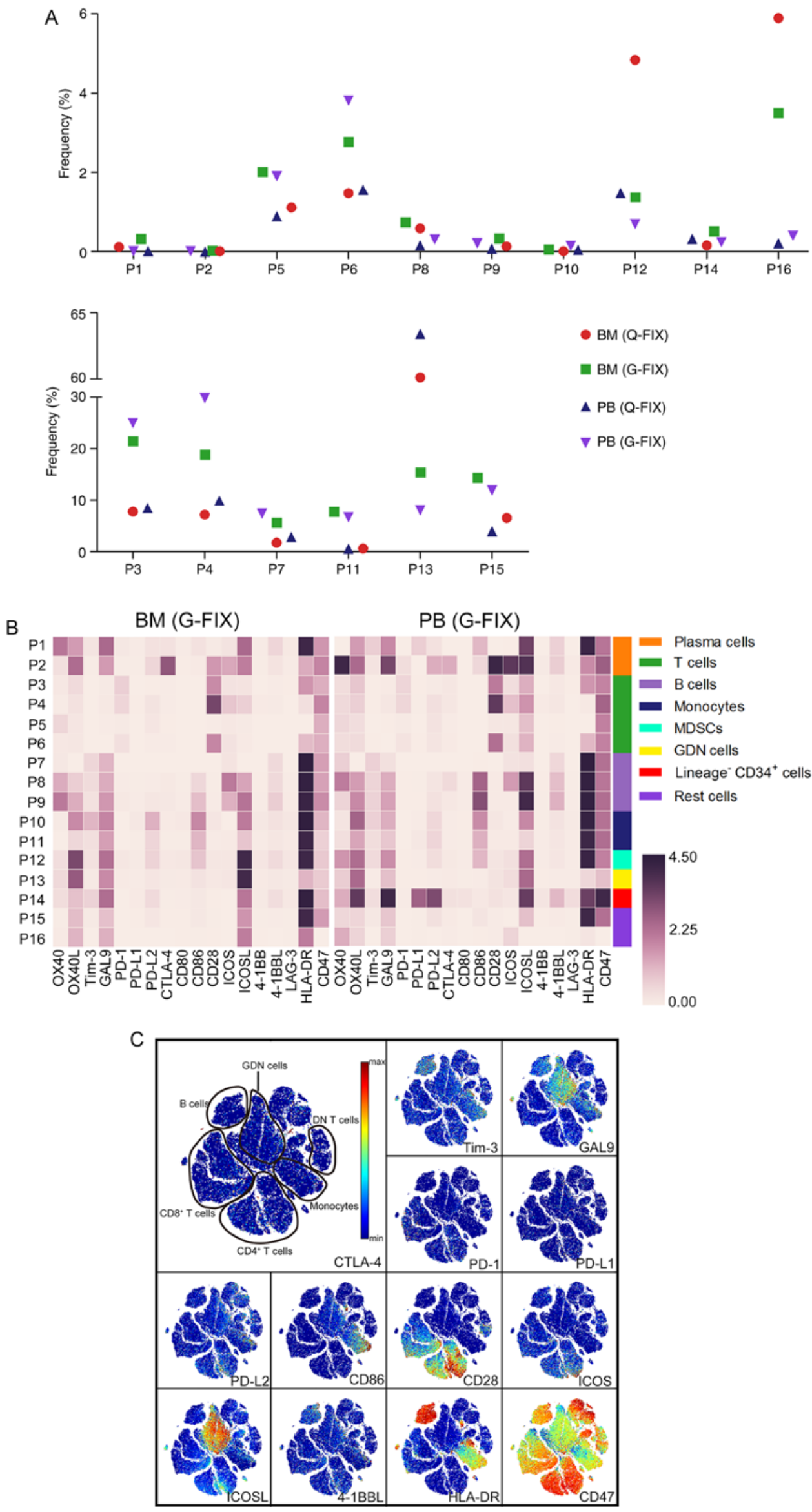

Figure 6. Onco-immune atlas in PB and BM cells of an solitary bone plasmacytoma (SBP) patient. (A) Frequency of immune lineages for each sample collected from the SBP patient's PB or BM. (B) Heatmaps showing the normalized mean expression of 18 immunomodulatory molecules in all cell populations. Cell types are indicated by color. (C) viSNE maps displaying PB (G-FIX) cells from the SBP patient and colored by the normalized mean expression of the indicated immunomodulatory molecules. 

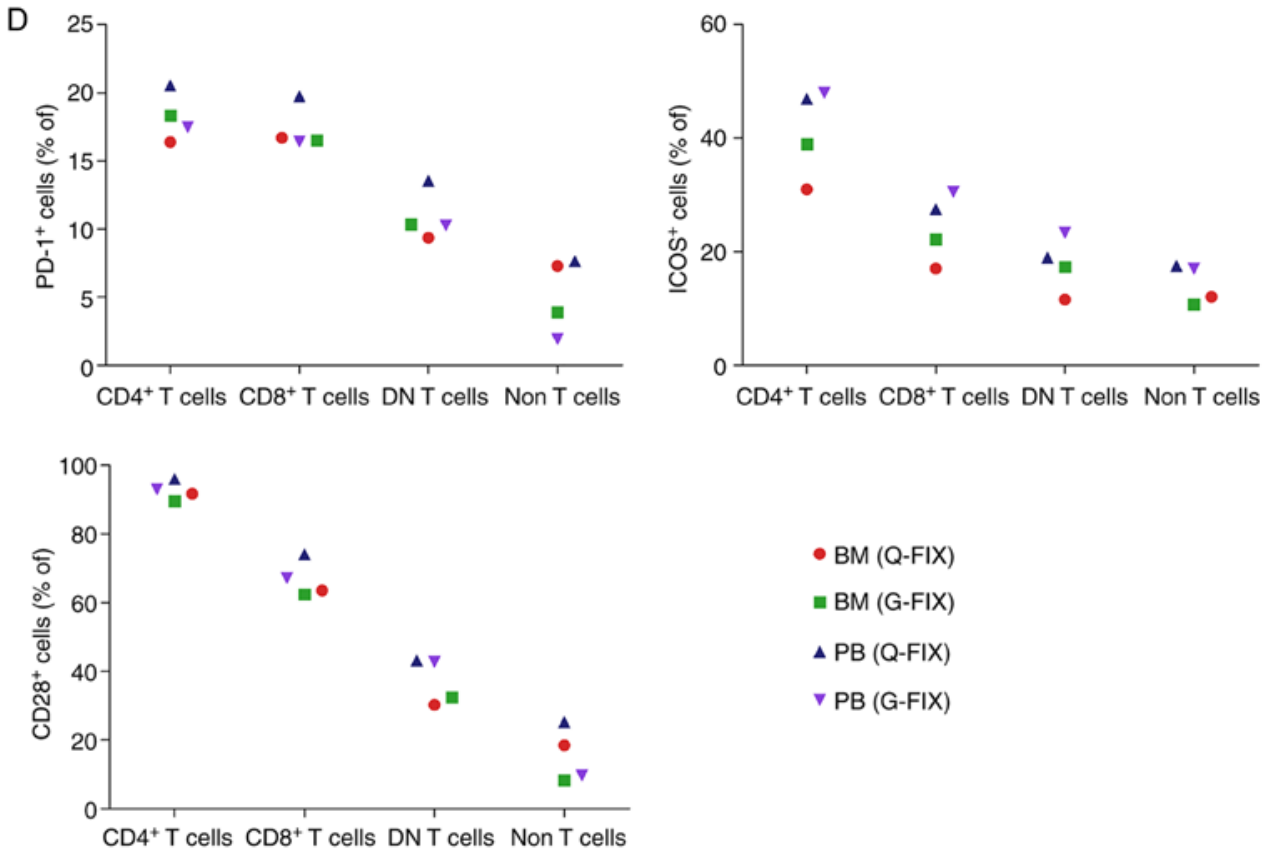

E
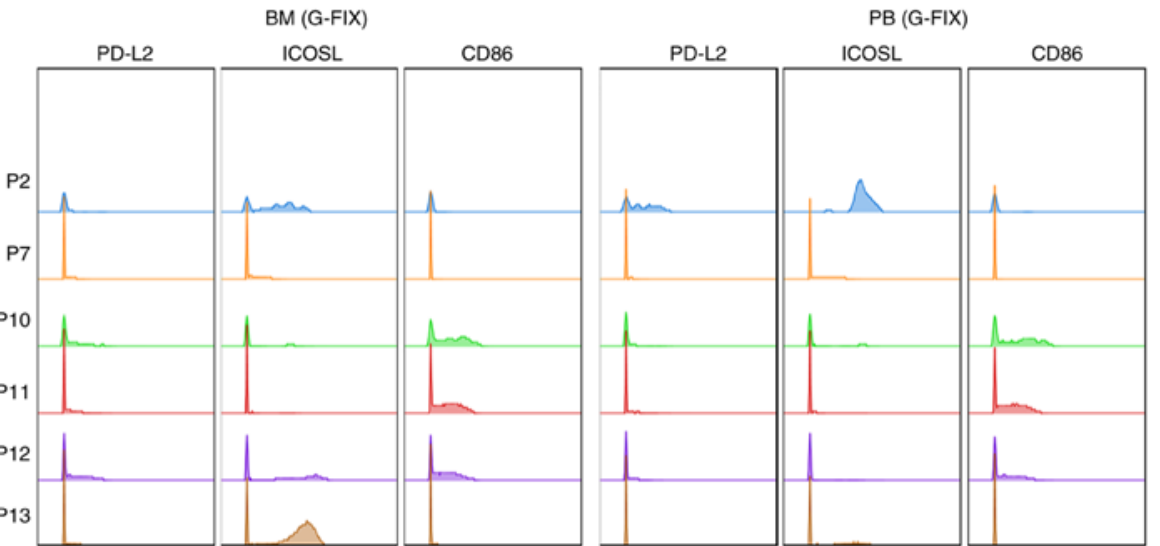

$\mathrm{F}$
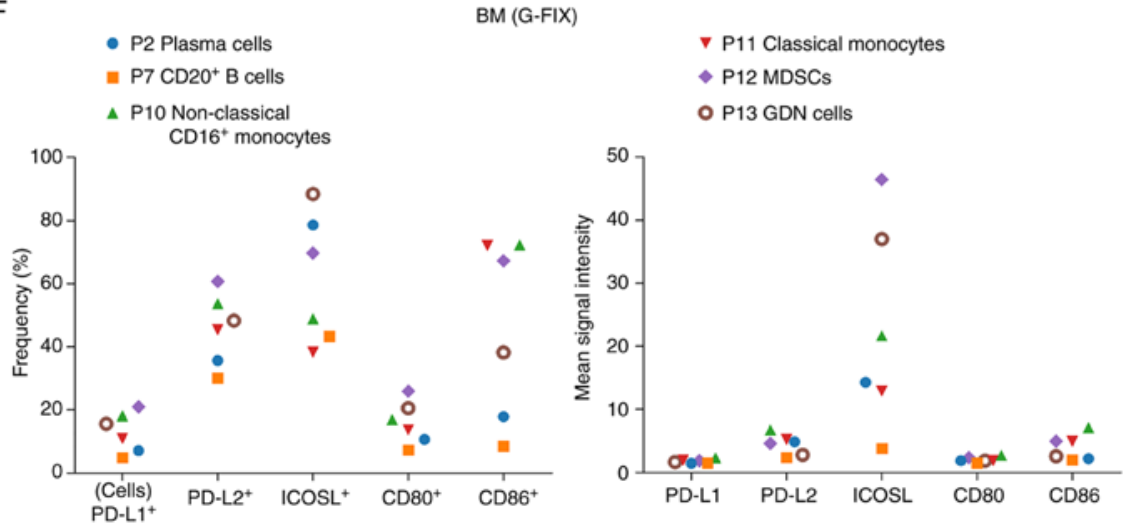

Figure 6. Continued. (D) Frequency of $\mathrm{PD}-1^{+}, \mathrm{ICOS}^{+}$, or $\mathrm{CD} 28^{+}$cells in the indicated populations for each sample collected from the SBP patient's PB or BM (E) Histograms showing the expression of the indicated ligands in certain populations of BM (G-FIX) or PB (G-FIX) cells. (F) Frequency of the indicated subsets in certain populations of BM (G-FIX) cells (left) and the mean signal intensity of the indicated ligands (right) among the positive cells of certain populations. PB, peripheral blood; BM, bone marrow; MDSCs, myeloid-derived suppressor cells; Q-FIX, fixed directly; G-FIX, fixed after MC isolation.

plasma cells $(0.12 \%)$ was detected in the BM by mass cytometry (Fig. 6A). After manual gating, the frequency of cell populations, the expression of immunomodulatory molecules in these populations, and two-dimensional maps showing all marker expression levels were analyzed (Figs. 6B; S6A and B). Because the expression of PD-1, ICOS, and CD28 was observed in the $\mathrm{T}$ cell populations on the viSNE maps (Fig. 6C), we gated and analyzed these cells. In all, 15-20\% of $\mathrm{PD}-1^{+}$cells were detected in $\mathrm{CD}^{+}{ }^{+}$or $\mathrm{CD} 8^{+} \mathrm{T}$ cells. The percentage of $\mathrm{ICOS}^{+}$cells among $\mathrm{CD}^{+}{ }^{+} \mathrm{T}$ cells $(30-48 \%)$ was greater than that among $\mathrm{CD}^{+}$cells $(17-30 \%)$. In total, $90-96 \%$ of $\mathrm{CD}^{+} \mathrm{T}$ cells and $60-70 \%$ of $\mathrm{CD}^{+} \mathrm{T}$ cells expressed CD28 
A

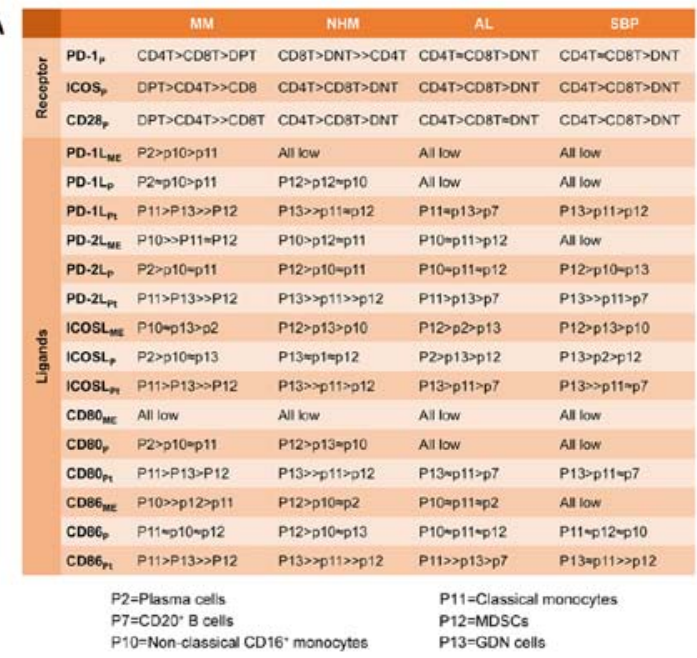

B
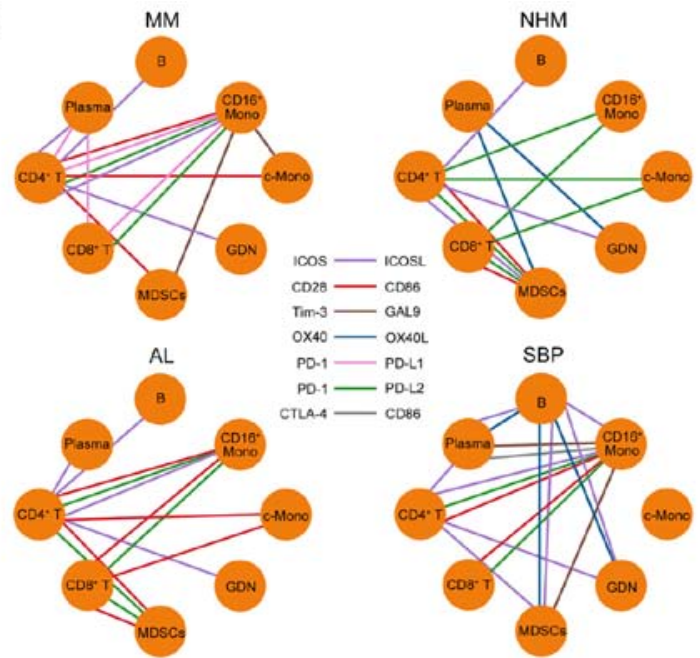

Figure 7. Immune checkpoints crosstalk in each patient. (A) Ranks of top 3 providers of each receptor or ligand in each patient's BM. ME, mean expression on positive cells; $\mathrm{P}$, percentage of positive cells in subpopulation; Pt, percentage of positive cells in total cells. (B) The predicted interaction network of immunomodulatory receptors and ligands between cell populations based on their expression in different cell populations. MM, multiple myeloma; NHM, non-hematologic malignancy; AL, amyloid light-chain; SBP, solitary bone plasmacytoma; MDSC, myeloid-derived suppressor cells; B, B cells; GDN, granulocytes, dendritic, and natural killer; Mono, monocytes; c-Mono, classical monocytes.

(Fig. 6D). Notably, less than $1 \%$ of $\mathrm{CD}^{+}$and only $4-8 \%$ of $\mathrm{CD}^{+} \mathrm{T}$ cells were activated in this patient (Fig. S6C). Nevertheless, these activated cells expressed higher levels of PD-1, ICOS, and CD28 (Fig. S6D). In this patient, a minimal number of non-T cells expressed PD-L1 and CD80, while PD-L2, ICOSL, and CD86 were provided by plasma cells, monocytes, MDSCs, and GDN cells (Fig. 6E and F).

\section{Discussion}

Although immune checkpoint blockade has been approved for the treatment of advanced cancer of various histological types, a low overall response rate and treatment failure occur in a significant proportion of patients partially due to inter-individual differences in the phenotype of immune regulatory checkpoints (21). To improve the understanding of personal immunity changes in plasma cell dyscrasias (PCD) patients, we introduced and validated the mass cytometry-based single-cell analysis of immune regulatory checkpoints in individuals. The sharp inter-individual heterogeneity among patients in the immunologic milieu and unambiguous immune checkpoints networks we explored here emphasizes the value and necessity of identifying an individual's immune atlas for selecting the optimum immunotherapy. Moreover, immune checkpoint-related receptors and ligands in individuals were summarized, and their expression levels, as well as top 3 providers, were ranked (Fig. 7A), thus providing an integrative immune checkpoint information for these patients. Additionally, our high-dimensional dataset not only validates prior observations but also provides the immune checkpoint network for each patient (Fig. 7B).

In multiple myeloma (MM), bone marrow (BM) represents a complex microenvironment with substantial immunosuppressive elements, including soluble factors, suppressive extracellular vesicles, myeloid-derived suppressor cells (MDSCs), regulatory T cells, and MM cells that consistently provide suppressive signals $(39,40)$. MM cells express PD-L1, which is not expressed on plasma cells obtained from monoclonal gammopathy of undetermined significance or healthy donors (41). Enriched PD-1 is expressed on circulating T cells isolated from advanced MM patients compared to normal volunteers and its expression in MM patients returns to normal levels following autologous transplantation (34). In keeping with these findings, our mass cytometry results from a single MM patient confirmed the elevated expression of programmed death ligand 1 (PD-L1) on MM cells and discovered the presence of $\mathrm{PD}-1$-expressing $\mathrm{CD}^{+}$and $\mathrm{CD}^{+} \mathrm{T}$ cells in the $\mathrm{BM}$ and PB. Specifically, BM T cells, except CD28 $8^{+}$cells, expressed higher levels of PD-1 and ICOS than PB T cells. In addition, PD-L2, a second ligand for PD-1, which has been demonstrated to inhibit $\mathrm{T}$ cell receptor-mediated proliferation and cytokine production by $\mathrm{CD}^{+} \mathrm{T}$ cells (42), was also expressed in MM cells, as well as in monocytes and MDSCs.

As another immune regulatory checkpoint at the forefront of immunotherapy for cancer, cytotoxic T lymphocyte-associated protein 4 (CTLA-4) expression was only detected in small amounts $(<10 \%)$ of $\mathrm{T}$ cells in the MM patient. In contrast, Zelle-Rieser et al demonstrated that the median percentages of CTLA- $4^{+}$cells among $\mathrm{CD}^{+}{ }^{+}$and $\mathrm{CD}^{+} \mathrm{T}$ cells in the $\mathrm{BM}$ are 60.5 and $65.8 \%$, respectively; these percentages are 56.7 and $64.7 \%$ in $\mathrm{PB} \mathrm{CD} 4^{+}$and $\mathrm{CD}^{+} \mathrm{T}$ cells, respectively, as summarized from 16 newly diagnosed MM patients (43). However, another early study reported a much lower proportion $(<10 \%)$ of CTLA- $4^{+}$cells among $\mathrm{PB} \mathrm{CD} 4^{+}$and $\mathrm{CD}^{+} \mathrm{T}$ cells from 22 MM patients and demonstrated a gradual decrease in CTLA-4 expression on T cells with advancing stage (44). These contradictory findings may be due to different antibody clones or detection methods used in these studies.

Indeed, blockade of the PD1-PDL1 pathway using CT-011, an anti PD-1 antibody, enhances the CTL- and natural killer (NK) cell-mediated killing of MM cells $(34,45,46)$ and anti-PD-L2 antibody-mediated blocking of the PD1-PDL-2 axis can increase the cytotoxicity of in vitro-expanded NK cells targeting MM cells (47), suggesting that PD-1 
signaling is an important element contributing to tumor-mediated immune suppression. However, as reported by a phase $1 \mathrm{~b}$ clinical trial, the single use of nivolumab, a Food and Drug Administration-approved PD-1 inhibitor, did not lead to disease regression in relapsed MM patients $(48,49)$, suggesting the existence of other decisive contributors to immunosuppression. Of note, a large proportion of $\mathrm{CD} 4^{+}$and $\mathrm{CD} 8^{+} \mathrm{T}$ cells was activated even though the MM load in the BM was very low. These activated $\mathrm{CD} 4^{+} \mathrm{T}$ cells express higher levels of PD- 1 and ICOS, as well as CD28, which is a key T cell co-stimulatory receptor that binds to $\mathrm{B} 7$ molecules (50), whereas activated $\mathrm{CD} 8^{+} \mathrm{T}$ cells express higher levels of PD- 1 and ICOS but barely express CD28. Downregulation of CD28 is a feature of both exhaustion and senescence in T cells (51) and is detected in $\mathrm{T}$ cells from high-risk smoldering MM patients compared to healthy individuals (52). Thus, $\mathrm{CD} 8^{+} \mathrm{T}$ cells were initially activated and subsequently exhausted by MM cells to favor the immune escape of cancer cells. Two recent studies have provided substantial evidence indicating that $\mathrm{CD} 28$ is strongly preferred as a target of PD-1 signaling and that the rescue of exhausted $\mathrm{CD} 8^{+} \mathrm{T}$ cells by PD-1/PD-L1 blockade is CD28 dependent $(53,54)$. These novel findings, in combined with our result that most $\mathrm{MM} \mathrm{CD}^{+}$T cells lack $\mathrm{CD} 28$ expression, can at least partially explain why PD-1/PD-L1 blockade alone cannot alleviate MM progression. According to the personal immune atlas discovered in the MM patient, we can use a combination of PD-1/PD-L1 blockade with strategies that restore and strengthen CD28 signaling to improve immunotherapy.

In the MM patient, a clear subset of $\mathrm{CD} 4^{+} \mathrm{T}$ cells expressed ICOS, which is a mediator and regulator of helper $\mathrm{T}$ cell immunity and effector $\mathrm{T}$ cell differentiation (55), and several cell populations, including MM cells, MDSCs, and monocytes, provide its ligand, ICOSL, for them. In keeping with this mechanism, a previous study has reported that MM patients present a higher percentage of $\mathrm{ICOS}^{+}$cells in follicular helper $\mathrm{T}$ cells than healthy controls (56). In an in vitro experiment, ICOS/ICOSL blockade significantly inhibited the generation of $\mathrm{MM}$ cell-induced $\mathrm{T}_{\mathrm{Reg}}\left(\mathrm{CD} 4^{+} \mathrm{CD} 25^{+} \mathrm{FoxP}^{+}\right)$cells (57), and lenalidomide, a clinically verified anti-MM immunomodulatory drug, downregulated ICOSL expression in MM cells (58) and enhanced PD-1/PD-L1 blockade-induced immune response in MM patients (59), underscoring ICOS/ICOSL blockade as a possible anti-MM immunotherapeutic sponsor and enhancer. The fact that large numbers of granulocytes removed by density gradient centrifugation offer the highest expression of PD-L1 and ICOSL highlights the importance of granulocytes in regulating immune-checkpoints. Thus, these cells should be considered when developing new immunotherapeutic strategies.

Very few details of immune checkpoints in AL and SBP patients have been discovered. Our results directly provide comprehensive insights into the immune status of these individual patients. In these patients, we were unable to detect a large proportion of activated (HLA-DR $\left.{ }^{+} \mathrm{CD} 38^{+}\right)$and exhausted $\left(\mathrm{CD} 28^{-}\right) \mathrm{CD}^{+} \mathrm{T}$ cells. Although $>50 \%$ of $\mathrm{CD} 28^{+}$cells were detected in $\mathrm{CD}^{+} \mathrm{T}$ cell population from these 3 patients, the activation of these cells was deficient, indicating a lack of stimulators. Because malignant plasma cells are located in various bone tissues in AL amyloidosis, and solitary bone plasmacytoma (SBP) patients, the absence of these cells in the ilium BM may be the cause of $\mathrm{CD} 8^{+} \mathrm{T}$ cell inactivation. Predictably, the discovery of the state of PD-1, ICOS, and CD28 expression on T cells and the providers for their ligands in an individual patient will direct the formulation of personalized treatment. Importantly, other immune checkpoints axes, including inhibitory signaling by Tim-3-GAL9 and LAG-3-HLA-DR (60), and the stimulatory pathways OX40-OX40L and 4-1BB-4-1BBL $(61,62)$, are more or less presented in multiple cell subsets aside from $\mathrm{T}$ cells. These interactions ought to be meaningful for understanding the immune regulation in the tumor microenvironment during malignant neoplasm development, and they need to be validated in the future. Moreover, the strong expression of CD47 which serves as an inhibitory receptor, was widely detected in the malignant plasma cells and leukocytes of all 4 patients. Elevated CD47 expression has been shown to regulate tumor metastasis and dissemination in several hematologic malignancies and to be associated with a poorer clinical prognosis (63). CD47 blockade stimulates the phagocytosis of cancer cells by macrophages and triggers the T cell-mediated death of immunogenic tumors (64). Furthermore, a variety of therapeutics targeting CD47 singling are currently under investigation in preclinical models and clinical trials for both solid and hematologic malignancies (65). The common expression of CD47 found in these 3 PCD patients provides a clinical indication for targeting this pathway.

Although our findings provide extensive systemic onco-immune information for individuals, several underlying limitations are raised with it. First, our antibody panel only covers the markers for gating general cell populations due to the restriction of available channels, leading to the missing of detailed information in T cell subsets, NK cells, and dendritic cell (DC) clusters. Second, data collected by mass cytometry from individuals were finely analyzed by various verified computational analyses, but follow-up preclinical and clinical studies are needed to validate these information-conducted precision medicine approaches. Third, although the main objective of this study was to explore the personal immunologic milieu using mass cytometry technology, the quantity of cases was low; therefore, single-cell analysis of more patients and healthy donors should be performed to discover changes in the regulation of immune checkpoints in specific PCD subtypes. Nevertheless, our successful identification of the personalized immune atlas in these patients demonstrates the promise of applying mass cytometry-based single-cell analysis for better understanding the immune transition during cancer progression and in monitoring the individual onco-immune status, thereby promoting the selection of appropriate immunotherapies and concretely benefitting patients.

\section{Acknowledgements}

We thank Professor Yongliang Huo from Guangzhou Medical University for critical review of the manuscript.

\section{Funding}

This study was supported by the National Natural Science Foundation of China (grant nos. 81700203 and 81970193) and the Guangdong Basic and Applied Basic Research Foundation (project nos. 2019A1515011126 and 2019A1515011327). 


\section{Availability of data and materials}

The data that support the findings of this study are available from the corresponding author upon reasonable request.

\section{Authors' contributions}

JW conceived the research idea and supervised the experiments. JW implemented the experiments together with assistance from CT,YZ and HZ. YZ collected the samples from the patients. $\mathrm{JW}, \mathrm{CT}$ and $\mathrm{HZ}$ analyzed the data and wrote the manuscript with suggestions from YZ. All authors read and approved the final manuscript and agree to be accountable for all aspects of the research in ensuring that the accuracy or integrity of any part of the work are appropriately investigated and resolved.

\section{Ethics approval and consent to participate}

Patient samples were collected from patients at the Third Affiliated Hospital of Sun Yat-sen University (Guangzhou, Guangdong, China) after obtaining patient informed consent. All protocols were reviewed and approved by the Third Affiliated Hospital of Sun Yat-sen University Ethics Committee.

\section{Patient consent for publication}

Not applicable.

\section{Competing interests}

The authors declare that they have no competing interests.

\section{References}

1. Newell EW and Cheng Y: Mass cytometry: Blessed with the curse of dimensionality. Nat Immunol 17: 890-895, 2016.

2. Spitzer MH and Nolan GP: Mass cytometry: Single cells, many features. Cell 165: 780-791, 2016.

3. Wang Z, Gerstein M and Snyder M: RNA-Seq: A revolutionary tool for transcriptomics. Nat Rev Genet 10: 57-63, 2009.

4. Stegle O, Teichmann SA and Marioni JC: Computational and analytical challenges in single-cell transcriptomics. Nat Rev Genet 16: 133-145, 2015.

5. Bendall SC, Simonds EF, Qiu P, Amir el-AD, Krutzik PO, Finck R, Bruggner RV, Melamed R, Trejo A, Ornatsky OI, et al: Single-cel mass cytometry of differential immune and drug responses across a human hematopoietic continuum. Science 332: 687-696, 2011.

6. Bodenmiller B, Zunder ER, Finck R, Chen TJ, Savig ES, Bruggner RV, Simonds EF, Bendall SC, Sachs K, Krutzik PO and Nolan GP: Multiplexed mass cytometry profiling of cellular states perturbed by small-molecule regulators. Nat Biotechnol 30: 858-867, 2012.

7. Bendall SC, Davis KL, Amir el-AD, Tadmor MD, Simonds EF, Chen TJ, Shenfeld DK, Nolan GP and Pe'er D: Single-cell trajectory detection uncovers progression and regulatory coordination in human B cell development. Cell 157: 714-725, 2014.

8. Good Z, Sarno J, Jager A, Samusik N, Aghaeepour N, Simonds EF, White L, Lacayo NJ, Fantl WJ, Fazio G, et al: Single-cell developmental classification of $\mathrm{B}$ cell precursor acute lymphoblastic leukemia at diagnosis reveals predictors of relapse. Nat Med 24: 474-483, 2018

9. Behbehani GK, Bendall SC, Clutter MR, Fantl WJ and Nolan GP Single-cell mass cytometry adapted to measurements of the cell cycle. Cytometry A 81: 552-566, 2012.

10. Knapp DJ, Hammond CA, Aghaeepour N, Miller PH, Pellacani D, Beer PA, Sachs K, Qiao W, Wang W, Humphries RK, et al: Distinct signaling programs control human hematopoietic stem cell survival and proliferation. Blood 129: 307-318, 2017.
11. Porpiglia E, Samusik N, Ho ATV, Cosgrove BD, Mai T, Davis KL, Jager A, Nolan GP, Bendall SC, Fantl WJ and Blau HM: High-resolution myogenic lineage mapping by single-cell mass cytometry. NaT Cell Biol 19: 558-567, 2017.

12. Qiu P, Simonds EF, Bendall SC, Gibbs KD Jr, Bruggner RV, Linderman MD, Sachs K, Nolan GP and Plevritis SK: Extracting a cellular hierarchy from high-dimensional cytometry data with SPADE. Nat Biotechnol 29: 886-891, 2011.

13. Amir el-AD, Davis KL, Tadmor MD, Simonds EF, Levine JH, Bendall SC, Shenfeld DK, Krishnaswamy S, Nolan GP and Pe'er D: viSNE enables visualization of high dimensional single-cell data and reveals phenotypic heterogeneity of leukemia. Nat Biotechnol 31: 545-552, 2013.

14. Lavin Y, Kobayashi S, Leader A, Amir ED, Elefant N, Bigenwald C, Remark R, Sweeney R, Becker CD, Levine JH, et al: Innate immune landscape in early lung adenocarcinoma by paired single-cell analyses. Cell 169: 750-765.e17, 2017.

15. Minn AJ and Wherry EJ: combination cancer therapies with immune checkpoint blockade: Convergence on interferon signaling. Cell 165: 272-275, 2016.

16. June $\mathrm{CH}, \mathrm{O}^{\prime}$ Connor RS, Kawalekar OU, Ghassemi S and Milone MC: CAR T cell immunotherapy for human cancer. Science 359: 1361-1365, 2018.

17. Syn NL, Teng MWL, Mok TSK and Soo RA: De-novo and acquired resistance to immune checkpoint targeting. Lancet Oncol 18: e731-e741, 2017.

18. Dougall WC, Roman Aguilera A and Smyth MJ: Dual targeting of RANKL and PD-1 with a bispecific antibody improves anti-tumor immunity. Clin Transl Immunol 8: e01081, 2019.

19. Topalian SL, Taube JM, Anders RA and Pardoll DM: Mechanism-driven biomarkers to guide immune checkpoint blockade in cancer therapy. Nat Rev Cancer 16: 275-287, 2016.

20. Oliver AJ, Davey AS, Keam SP, Mardiana S, Chan JD, von Scheidt B, Beavis PA, House IG, Van Audernaerde JR, Darcy PK, et al: Tissue-specific tumor microenvironments influence responses to immunotherapies. Clin Transl Immunol 8: e1094, 2019.

21. Pitt JM, Vétizou M, Daillère R, Roberti MP, Yamazaki T, Routy B, Lepage P, Boneca IG, Chamaillard M, Kroemer G and Zitvogel L: Resistance mechanisms to immune-checkpoint blockade in cancer: Tumor-intrinsic and -extrinsic factors. Immunity 44: 1255-1269, 2016.

22. Wilson RAM, Evans TRJ, Fraser AR and Nibbs RJB: Immune checkpoint inhibitors: New strategies to checkmate cancer. Clin Exp Immunol 191: 133-148, 2018.

23. Marhelava K, Pilch Z, Bajor M, Graczyk-Jarzynka A and Zagozdzon R: Targeting negative and positive immune checkpoints with monoclonal antibodies in therapy of cancer. Cancers 11: 1756, 2019.

24. Bhandaru M and Rotte A: monoclonal antibodies for the treatment of melanoma: Present and future strategies. Methods Mol Biol 1904: 83-108, 2019.

25. Rowshanravan B, Halliday N and Sansom DM: CTLA-4: A moving target in immunotherapy. Blood 131: 58-67, 2018.

26. Ribas A and Wolchok JD: Cancer immunotherapy using checkpoint blockade. Science 359: 1350-1355, 2018.

27. Jiang C, Cao S, Li N, Jiang L and Sun T: PD-1 and PD-L1 correlated gene expression profiles and their association with clinical outcomes of breast cancer. Cancer Cell Int 19: 233, 2019.

28. Wang X, Guo G, Guan H, Yu Y, Lu J and Yu J: Challenges and potential of PD-1/PD-L1 checkpoint blockade immunotherapy for glioblastoma. J Exp Clin Cancer Res 38: 87, 2019.

29. Gettinger S, Choi J, Hastings K, Truini A, Datar I, Sowell R, Wurtz A, Dong W, Cai G, Melnick MA, et al: Impaired HLA class I antigen processing and presentation as a mechanism of acquired resistance to immune checkpoint inhibitors in lung cancer. Cancer Discov 7: 1420-1435, 2017.

30. Chevrier S, Levine JH, Zanotelli VRT, Silina K, Schulz D, Bacac M, Ries CH, Ailles L, Jewett MAS, Moch H, et al: An immune atlas of clear cell renal cell carcinoma. Cell 169: 736-749.e18, 2017.

31. Krieg C, Nowicka M, Guglietta S, Schindler S, Hartmann FJ, Weber LM, Dummer R, Robinson MD, Levesque MP and Becher B: High-dimensional single-cell analysis predicts response to anti-PD-1 immunotherapy. Nat Med 24: 144-153, 2018.

32. Heher EC, Goes NB, Spitzer TR, Raje NS, Humphreys BD, Anderson KC and Richardson PG: Kidney disease associated with plasma cell dyscrasias. Blood 116: 1397-1404, 2010.

33. Suen H, Brown R, Yang S, Ho PJ, Gibson J and Joshua D: The failure of immune checkpoint blockade in multiple myeloma with PD-1 inhibitors in a phase 1 study. Leukemia 29: 1621-1622, 2015. 
34. Rosenblatt J, Glotzbecker B, Mills H, Vasir B, Tzachanis D, Levine JD, Joyce RM, Wellenstein K, Keefe W, Schickler M, et al: PD-1 blockade by CT-011, anti-PD-1 antibody, enhances ex vivo T-cell responses to autologous dendritic cell/myeloma fusion vaccine. J Immunother 34: 409-418, 2011.

35. Ray A, Das DS, Song Y, Richardson P, Munshi NC, Chauhan D and Anderson KC: Targeting PD1-PDL1 immune checkpoint in plasmacytoid dendritic cell interactions with T cells, natural killer cells and multiple myeloma cells. Leukemia 29: 1441-1444, 2015.

36. Jelinek T, Paiva B and Hajek R: Update on PD-1/PD-L1 inhibitors in multiple myeloma. Front Immunol 9: 2431, 2018.

37. Kotecha N, Krutzik PO and Irish JM: Web-based analysis and publication of flow cytometry experiments. Curr Protoc Cytom 10: Unit 10, 2010.

38. Maecker HT, McCoy JP and Nussenblatt R: Standardizing immunophenotyping for the human immunology project. Nat Rev Immunol 12: 191-200, 2012

39. Wang J, Hendrix A, Hernot S, Lemaire M, De Bruyne E, Van Valckenborgh E, Lahoutte T, De Wever O, Vanderkerken K and Menu E: Bone marrow stromal cell-derived exosomes as communicators in drug resistance in multiple myeloma cells. Blood 124: 555-566, 2014.

40. Wang J, De Veirman K, Faict S, Frassanito MA, Ribatti D, Vacca A and Menu E: Multiple myeloma exosomes establish a favourable bone marrow microenvironment with enhanced angiogenesis and immunosuppression. J Pathol 239: 162-173, 2016.

41. Liu J, Hamrouni A, Wolowiec D, Coiteux V, Kuliczkowski K Hetuin D, Saudemont A and Quesnel B: Plasma cells from multiple myeloma patients express B7-H1 (PD-L1) and increase expression after stimulation with IFN-\{gamma\} and TLR ligands via a MyD88-, TRAF6-, and MEK-dependent pathway. Blood 110: 296-304, 2007.

42. Latchman Y, Wood CR, Chernova T, Chaudhary D, Borde M, Chernova I, Iwai Y, Long AJ, Brown JA, Nunes R, et al: PD-L2 is a second ligand for PD-1 and inhibits T cell activation. Nat Immunol 2: 261-268, 2001

43. Zelle-Rieser C, Thangavadivel S, Biedermann R, Brunner A, Stoitzner P, Willenbacher E, Greil R and Jöhrer K: T cells in multiple myeloma display features of exhaustion and senescence at the tumor site. J Hematol Oncol 9: 116, 2016.

44. Mozaffari F, Hansson L, Kiaii S, Ju X, Rossmann ED, Rabbani H, Mellstedt $\mathrm{H}$ and Osterborg A: Signalling molecules and cytokine production in $\mathrm{T}$ cells of multiple myeloma-increased abnormalities with advancing stage. Br J Haematol 124: 315-324, 2004.

45. Benson DM Jr, Bakan CE, Mishra A, Hofmeister CC, Efebera Y, Becknell B, Baiocchi RA, Zhang J, Yu J, Smith MK, et al: The PD-1/PD-L1 axis modulates the natural killer cell versus multiple myeloma effect: A therapeutic target for CT-011, a novel monoclonal anti-PD-1 antibody. Blood 116: 2286-2294, 2010

46. Dong W, Wu X, Ma S, Wang Y, Nalin AP, Zhu Z, Zhang J, Benson DM, He K, Caligiuri MA and Yu J: The mechanism of anti-PD-L1 antibody efficacy against PD-L1-negative tumors identifies NK cells expressing PD-L1 as a cytolytic effector. Cancer Discov 9: 1422-1437, 2019.

47. Guo Y, Feng X, Jiang Y, Shi X, Xing X, Liu X, Li N, Fadeel B and Zheng $C$ : PD1 blockade enhances cytotoxicity of in vitro expanded natural killer cells towards myeloma cells. Oncotarget 7: 48360-48374, 2016.

48. Lesokhin AM, Ansell SM, Armand P, Scott EC, Halwani A, Gutierrez M, Millenson MM, Cohen AD, Schuster SJ, Lebovic D, et al: Nivolumab in patients with relapsed or refractory hematologic malignancy: Preliminary results of a phase $\mathrm{Ib}$ study. J Clin Oncol 34: 2698-2704, 2016.

49. Rosenblatt J and Avigan D: Targeting the PD-1/PD-L1 axis in multiple myeloma: A dream or a reality? Blood 129: 275-279, 2017.
50. Esensten JH, Helou YA, Chopra G, Weiss A and Bluestone JA: CD28 costimulation: From mechanism to therapy. Immunity 44: 973-988, 2016.

51. Akbar AN and Henson SM: Are senescence and exhaustion intertwined or unrelated processes that compromise immunity? Nat Rev Immunol 11: 289-295, 2011.

52. Paiva B, Mateos MV, Sanchez-Abarca LI, Puig N, Vidriales MB, López-Corral L, Corchete LA, Hernandez MT, Bargay J, de Arriba F, et al: Spanish myeloma group/program study and treatment of hematological malignancies cooperative study groups: Immune status of high-risk smoldering multiple myeloma patients and its therapeutic modulation under LenDex: A longitudinal analysis. Blood 127: 1151-1162, 2016.

53. Hui E, Cheung J, Zhu J, Su X, Taylor MJ, Wallweber HA, Sasmal DK, Huang J, Kim JM, Mellman I and Vale RD: $\mathrm{T}$ cell costimulatory receptor CD28 is a primary target for PD-1-mediated inhibition. Science 355: 1428-1433, 2017.

54. Kamphorst AO, Wieland A, Nasti T, Yang S, Zhang R, Barber DL, Konieczny BT, Daugherty CZ, Koenig L, Yu K, et al: Rescue of exhausted CD8 T cells by PD-1-targeted therapies is CD28-dependent. Science 355: 1423-1427, 2017.

55. Wikenheiser DJ and Stumhofer JS: ICOS co-stimulation: Friend or foe? Front Immunol 7: 304, 2016.

56. Zhou DM, Xu YX, Zhang LY, Sun Y, Wang ZY, Yuan YQ and Fu JX: The role of follicular T helper cells in patients with malignant lymphoid disease. Hematology 22: 412-418, 2017.

57. Feyler S, Scott GB, Parrish C, Jarmin S, Evans P, Short M, McKinley K, Selby PJ and Cook G: Tumour cell generation of inducible regulatory $\mathrm{T}$-cells in multiple myeloma is contact-dependent and antigen-presenting cell-independent. PLoS One 7: e35981, 2012.

58. Scott GB, Carter C, Parrish C, Wood PM and Cook G: Downregulation of myeloma-induced ICOS-L and regulatory $\mathrm{T}$ cell generation by lenalidomide and dexamethasone therapy. Cell Immunol 297: 1-9, 2015.

59. Görgün G, Samur MK, Cowens KB, Paula S, Bianchi G, Anderson JE, White RE, Singh A, Ohguchi H, Suzuki R, et al: Lenalidomide enhances immune checkpoint blockade-induced immune response in multiple myeloma. Clin Cancer Res 21: 4607-4618, 2015.

60. Perez-Gracia JL, Labiano S, Rodriguez-Ruiz ME, Sanmamed MF and Melero I: Orchestrating immune check-point blockade for cancer immunotherapy in combinations. Curr Opin Immunol 27: 89-97, 2014

61. Goulding J, Tahiliani V and Salek-Ardakani S: OX40:OX40L axis: Emerging targets for improving poxvirus-based CD8(+) $\mathrm{T}$-cell vaccines against respiratory viruses. Immunol Rev 244: 149-168, 2011.

62. Chester C, Sanmamed MF, Wang J and Melero I: Immunotherapy targeting 4-1BB: Mechanistic rationale, clinical results, and future strategies. Blood 131: 49-57, 2018.

63. Chao MP, Weissman IL and Majeti R: The CD47-SIRP $\alpha$ pathway in cancer immune evasion and potential therapeutic implications. Curr Opin Immunol 24: 225-232, 2012.

64. Liu X, Pu Y, Cron K, Deng L, Kline J, Frazier WA, Xu H, Peng H, Fu YX and Xu MM: CD47 blockade triggers T cell-mediated destruction of immunogenic tumors. Nat Med 21: 1209-1215, 2015.

65. Weiskopf K: Cancer immunotherapy targeting the CD47/SIRPa axis. Eur J Cancer 76: 100-109, 2017.

(i) $\Theta$ This work is licensed under a Creative Commons Attribution-NonCommercial-NoDerivatives 4.0 International (CC BY-NC-ND 4.0) License. 